\title{
Geocronologia e aspectos estruturais e petrológicos do Pluton Bravo, Domínio Central da Província Borborema, Nordeste do Brasil: um granito transalcalino precoce no estágio pós-colisional da Orogênese Brasiliana
}

Geochronology and structural and petrological features of the Bravo Pluton, Central Domain of the Borborema Province,

Northeast Brazil: an early trans-alkaline granite in the post-collisional stage of the Brasiliano Orogeny

\section{Geysson de Almeida Lages ${ }^{1 *}$, Marcelo de Souza Marinho ${ }^{1}$, Marcos Antonio Leite do Nascimento ${ }^{2}$, Vladimir Cruz de Medeiros ${ }^{1}$, Elton Luiz Dantas ${ }^{3}$}

RESUMO: O Pluton Bravo (no Estado da Paraíba) constitui um stock elipsoidal formado por monzo/sienogranitos porfiríticos, enclaves dioritos e zonas híbridas. Está intrudido em gnaisses migmatíticos paleoproterozoicos do Domínio Central da Província Borborema. Os sienogranitos são metaluminosos a levemente peraluminosos, e exibem altas razóes de $\mathrm{K}_{2} \mathrm{O} / \mathrm{Na}_{2} \mathrm{O}>1,5$ e FeO $/\left(\mathrm{FeO}_{\mathrm{t}}+\mathrm{MgO}\right)>0,86$. Os dioritos possuem alto conteúdo de $\mathrm{Zr}(>1.134 \mathrm{ppm}), \mathrm{TiO}_{2}$ $1,6 \%$ e $\mathrm{Nb}>(49 \mathrm{ppm})$. As razóes $\left(\mathrm{La}_{\mathrm{N}} / \mathrm{Yb}_{\mathrm{N}}\right)_{\mathrm{N}}$ estáo entre 14 e 19,4, e $\left(\mathrm{Eu} / \mathrm{Eu}^{*}\right)_{N}$, entre 0,31 e 0,37 . As rochas do Pluton Bravo são moderadamente fracionadas com picos em $\mathrm{La}, \mathrm{Zr}$ e forte depressáo em $\mathrm{P}, \mathrm{Ti}$ e menor em Sr. Os dados plotam no campo discriminante de granitos pós-tectônicos/intraplaca. As estimativas de pressão (4,4 a 6,0 Kbar) baseadas no conteúdo de $\mathrm{Al}^{t}$ em anfibólio sugerem posicionamento do pluton na crosta superior a média. A temperatura do liquidus de acordo com o conteúdo de $\mathrm{Zr}$ e $\mathrm{SiO}_{2}$ oscilou entre 847 e $893^{\circ} \mathrm{C}$, e a de cristalização, calculada pelo par anfibólio-plagioclásio, entre 581 e $785^{\circ} \mathrm{C}$. Exibem idades-modelo $\mathrm{T}_{\mathrm{DM}}=2,35$ a 2,18 e $\varepsilon_{\mathrm{Nd}(580}$ $\mathrm{Mal}_{\mathrm{a}}=-18,32 \mathrm{a}-17,03$. A idade U-Pb (LA-MC-ICP-MS U-Th-Pb em zircão) indica cristalização ao redor de $581 \pm 2 \mathrm{Ma}$. A relação entre a idade de cristalização $(-580 \mathrm{Ma})$, as características químicas de granito tipo-A, idades-modelo $\mathrm{Sm}-\mathrm{Nd}$ maiores que 2,1 Ga e a associação com regime tectônico transcorrente contrastam com outros granitos similares, porém ligeiramente mais novos ( $-570 \mathrm{Ma})$, que ocorrem nos Domínios Central, Rio Grande do Norte e no leste da Nigéria.
ABSTRACT: The Bravo Pluton (State of Paraiba) is an ellipsoidal stock formed by porphyritic monzo/syenogranites, dioritic enclaves and their hybrid products. The granitic body is intruded in paleoproterozoic gneiss-migmatitic rocks of the Central Domain of the Borborema Province. The monzo/syenogranites are metaluminous to slightly peraluminous and exhibit high $\mathrm{K}_{2} \mathrm{O} / \mathrm{Na}_{2} \mathrm{O}>1.5$ and $\mathrm{FeO} /(\mathrm{FeO}+\mathrm{MgO})>0.86$. The diorites exhibit high contents of $\mathrm{Zr}(>1,134 \mathrm{ppm}), \mathrm{TiO}-1.6 \%$ and $\mathrm{Nb}>(49$ ppm). $(\mathrm{La} / \mathrm{Yb})_{N}$ is in between 14 and 19.4 and $\left(E u / E u^{*}\right)_{N}$ between 0.31 to 0.37 . In the spiderdiagram, the data are moderately fractionated with peaks in $\mathrm{La}, \mathrm{Zr}$ and strong negative anomalies in P, Ti and less in Sr. They plot in the field of post-tectonic/intraplate granites in the tectonic discriminant diagram, with some scattering. The estimated pressure (4.4 to 6.0 kbar) based on $A l^{t}$ content in amphibole suggest a range from the middle to the upper crust for the emplacement of the Bravo Pluton. The liquidus temperature according to $\mathrm{Zr}$ and $\mathrm{SiO}_{2}$ contents range from 847 to $893^{\circ} \mathrm{C}$ and for the crystallization, calculated by amphibole-plagioclase pairs range from 589$867^{\circ} \mathrm{C}$. They show $T_{\text {mu }}$ model ages ranging from 2.35 to 2.18 and $\varepsilon_{\text {uuse }}$ $=-18.32$ to -17.03 . A crystallization age of $581 \pm 2 \mathrm{Ma}$ was obtained for the granite from LA-MC-ICP-MS U-Th-Pb method in zircon. The relationship between the crystallization age ( $-580 \mathrm{Ma})$, A-type geochemical characteristics of the granitoids, Nd model-ages greater than $2.1 \mathrm{Ga}$ and association with the strike-slip regime contrasts with other similar granitoids, furthermore, slight younger in age ( $570 \mathrm{Ma})$, which occur in Central, Rio Grande do Norte Domains and in eastern Nigeria. In this sense, the

\footnotetext{
Serviço Geológico do Brasil, Companhia de Pesquisa de Recursos Minerais - CPRM, Superintendência Regional de Recife - SUREG-RE, Recife (PE), Brasil. E-mails: geysson.lages@cprm.gov.br; marcelo.marinho@cprm.gov.br; vladimir.medeiros@cprm.gov.br

²Departamento de Geologia, Universidade Federal do Rio Grande do Norte - UFRN, Natal (RN), Brasil. E-mail: marcos@geologia.ufrn.br 3Instituto de Geociências, Campus Universitário Darcy Ribeiro, Universidade de Brasília - UnB, Brasília (DF), Brasil. E-mail: elton@unb.br *Autor correspondente.

Manuscrito ID: 20150033. Recebido em: 19/09/2015. Aprovado em: 22/02/2016
} 
Isso sugere que a transição do regime compressional para direcional/componente extensional precedeu no caso deste corpo evidenciando o caráter episódico e diacrônico da Orogênese Brasiliana. Conclui-se que o Pluton Bravo constitui um bom exemplo de magmatismo pós-colisional transalcalino no Domínio Central, que, com outros exemplos no Domínio Rio Grande do Norte e no leste da Nigéria, sugere um afinamento convectivo da litosfera subcontinental entre 580 e 570 Ma durante a consolidação do Supercontinente Gondwana.

PALAVRAS-CHAVE: Granitos ferrosos; Geocronologia; Mistura de magmas; Afinamento convectivo; Litosfera subcontinental.

\section{INTRODUÇÃO}

O período pós-colisional de um ciclo orogenético compreende o intervalo de tempo entre o principal evento de colisão continental e o desenvolvimento de um ambiente intraplaca (Liegeois 1998). Tal período é marcado pelo aumento nos gradientes geotermais, pelo desenvolvimento de extensa tectônica transcorrente a distensional e pela produçẫo de uma grande variedade de episódios magmáticos (Liegeois 1998; Bonin 2004; Nardi e Bitencourt 2009). O magmatismo associado a esse período apresenta uma maior complexidade entre as suítes ígneas, as quais incluem a interação entre magmas coexistentes, sugerindo fontes distintas entre a crosta e o manto litosférico e uma composição potássica a ultrapotássica como termo mais comum (Conticelli e Peccerillo 1992). Contudo, granitoides peraluminosos ricos em minerais de $\mathrm{Al}-\mathrm{Fe}-\mathrm{Mg}$ e suítes metaluminosas de características bimodais a granitoides alcalino-peralcalinos com componentes juvenis podem ocorrer com menor frequência (Bonin 2004).

No Domínio Central da Província Borborema, Nordeste do Brasil, o cenário pós-colisional da Orogênese Brasiliana (tardi-neoproterozoica) foi marcado pelo desenvolvimento de uma complexa rede de zonas de cisalhamento direcionais, associadas a um extenso magmatismo ediacarano (Vauchez et al. 1995; Jardim de Sá 1994). Na regiáo, esse magmatismo pode ser dividido entre um estágio transicional e um estágio póscolisional propriamente dito. O primeiro estágio é representado principalmente por extensos granitoides (monzogranitos a monzonitos) de suítes cálcio-alcalinas de alto K a shoshoníticas associados a K-dioritos com características de granitos tipo-I e intrusivos entre 595 e $576 \mathrm{Ma}$ (Guimarães et al. 2004; Van Schmus et al. 2011). Tal transição marca a passagem de um regime de deformaçáo compressional para dominantemente transcorrente (Van Schmus et al. 2011; Guimarães et al. 2004). Nesse caso, as intrusōes possuem variado conteúdo de $\mathrm{SiO}_{2}$, alto conteúdo de $\mathrm{K}_{2} \mathrm{O}(>4 \%), \# \mathrm{Fe}\left[\mathrm{FeO}_{\mathrm{t}} / \mathrm{FeO}_{\mathrm{t}}\right.$ $+\mathrm{MgO}](0,49-0,62)$, ausência de anomalia negativa de Eu, pequena depleçấo de Sr e idades-modelo $\mathrm{T}_{\mathrm{DM}}$ variando de 2,1 a 1,7 Ga (Van Schmus et al. 2011; Guimarães et al. 2004).

O estágio pós-colisional está mais bem representado nos granitos com ca. $570 \mathrm{Ma}$, que possuem características transition of the compressional to the directional regime (with an extensional component) has occurred just before in the case of this body showing an episodic and diachronic character of the Brazilian orogeny. We conclude that Bravo Pluton constitutes a good example of trans-alkaline post-collisional magmatism within Central Domain which together with other examples from Rio Grande do Norte Domain and in eastern Nigeria suggest a convective thinning of subcontinental lithosphere between 580-570 Ma during amalgamation of Gondwana Supercontinent.

KEYWORDS: Ferroan granitoids; Geochronology; Magma mixing; Convective thinning; Subcontinental lithosphere.

geoquímicas marcantes, como alto \#Fe $(0,77-0,95)$, fortes anomalias negativas de $\mathrm{Eu}, \mathrm{Sr}$ e $\mathrm{P}$, tendem a plotar no campo de granitos intraplaca e apresentam idades-modelo entre 2,5 e 2,0 Ga (Van Schmus et al. 2011; Guimarães et al. 2004). Zircóes herdados são comuns nos granitos desse estágio (Guimarães et al. 1998). É possível observar que esses corpos plutônicos refletem a mistura de diferentes fontes, sendo que nos granitoides transicionais da Província Borborema há uma maior interação de fontes mais jovens do que a dos granitos pós-colisionais.

Este artigo objetivou tratar dos aspectos estruturais, geoquímicos, geocronológicos e isotópicos do Pluton Bravo, buscando a sua contextualização no quadro tectônico da Província Borborema.

\section{MATERIAIS E MÉTODOS}

As amostras de rocha coletadas para litoquímica foram analisadas pelo Acme Analytical Laboratories Ltd. A abertura das rochas foi via fusão de metaborato de lítio e água-régia e as análises multielementares foram efetuadas por ICP-MS e ICP-AES (elementos traços e de terras-raras) e fluorescência de raios- $\mathrm{X}$ (elementos maiores) conforme grupo de elementos definidos pelo laboratório.

Os dados de química mineral foram obtidos para uma amostra do sienogranito (fácies grossa a porfirítica), da porção interna do pluton, utilizando-se a microssonda eletrônica JEOL, modelo JXA-8900RL, do Laboratório de Microanálises da Universidade Federal de Minas Gerais (UFMG). As calibraçôes utilizadas foram $15 \mathrm{kV}$ de voltagem de aceleração e 20 nA de corrente. O tempo de contagem em cada cristal disponível (TAP, PETJ, LIF) foi de $10,0 \mathrm{~s}$ e os padróes utilizados para os elementos analisados $(\mathrm{F}, \mathrm{Cl}, \mathrm{Fe}, \mathrm{Na}, \mathrm{K}$, $\mathrm{Mg}, \mathrm{Ca}, \mathrm{Al}, \mathrm{Ti}, \mathrm{Si}, \mathrm{Mn}$ ) foram, respectivamente: fluorita, $\mathrm{Cl}$-apatita, magnetita, jadeita, microclima, $\mathrm{MgO}$, wollastonita, $\mathrm{Al}_{2} \mathrm{O}_{3}$, rutilo, quartzo e rodonita.

As análises isotópicas de $\mathrm{Sm}-\mathrm{Nd}$ foram realizadas no Laboratório de Geocronologia da Universidade de Brasília (UnB) e seguiram o método descrito por Gióia e Pimentel (2000). 
Os dados isotópicos $\mathrm{U}-\mathrm{Pb}$ em zircão analisados por LA-MC-ICP-MS foram realizados no Laboratório de Geocronologia da UnB. Para esta análise, utilizou-se uma amostra do sienogranito (fácies grossa a porfirítica) coletada na entrada do Lajedo do Pai Mateus. Os concentrados de minerais pesados foram separados por meio de separação gravimétrica utilizando bateias; feito isso, os concentrados de zircóes foram separados por intermédio de separador magnético (Frantz isodynamic separator). Os grãos de zircão foram separados por catação manual, utilizando-se lupa binocular. Seguiram-se os métodos e procedimentos analíticos descritos por Bühn et al. (2009) e Matteini et al. (2009).

Imagens por retroespalhamento foram efetuadas utilizando um microscópio eletrônico de varredura com EDS acoplado, modelo FEI Quanta 450, utilizando os parâmetros WD - 10 mm e a voltagem de aceleração de $20 \mathrm{kV}$ pertencentes à Companhia de Pesquisa de Recursos Minerais (CPRM)/UnB.

\section{GEOLOGIA REGIONAL E SÍNTESES SOBRE A GRANITOGÊNESE}

A Província Borborema constitui uma unidade geotectônica consolidada no Ediacarano durante a Orogenia Brasiliana/Pan-africana. É composta por exposiçôes de embasamento paleoproterozoico, com fragmentos restritos de crosta arqueana, separados entre si por sequências supracrustais de idade meso e neoproterozoica e corpos plutônicos de idade e quimismo diverso (Almeida et al. 1977; Santos e Medeiros 1999). Em função da heterogeneidade dos blocos crustais que compóem a província, Santos $(1995,1996,2000)$ propôs um modelo evolutivo acrescionário para a região, pautado na amalgamação de diversos terrenos tectonoestratigráficos no decorrer de dois grandes ciclos orogenéticos, o Evento Cariris Velhos (1,1 0,95 Ga) e o Evento Brasiliano/Pan-africano (0,6 - 0,5 Ga). Nesse âmbito, o autor propôs uma divisão da província em 19 terrenos, agrupados em 5 domínios ou superterrenos: Externo, Central ou Zona Transversal, Rio Grande do Norte, Cearense e Médio Coreaú. Um modelo alternativo considera que a província consolidou-se durante a orogênese Riaciana-Orosiriana $(2,2$ - 2,0 Ga) e manteve-se relativamente coesa até o Neoproterozoico (Mariano et al. 1999; Neves e Mariano 2001; Neves 2003). Eventos tafrogênicos posteriores foram responsáveis apenas pelo desenvolvimento de riftes e/ou bacias oceânicas restritas, o que implicaria que toda deformação meso e/ou neoproterozoica ocorreu em ambiente intracontinental.

O Domínio Central ou Zona Transversal é limitado a norte pelo Domínio Rio Grande Norte e a sul pelo Domínio
Externo. Compreende um mosaico de segmentos crustais orientados segundo a direçâo NE-SW que apresentam características geológicas e assinaturas isotópicas distintas entre si. Esses segmentos correspondem aos terrenos Alto Moxotó, Alto Pajeú, Piancó-Alto Brígida e Rio Capibaribe (Santos 1996, 2000; Santos e Medeiros 1999).

O terreno Alto Moxotó na parte leste da Província Borborema (Fig. 1) é representado majoritariamente por unidades paleoproterozoicas e é limitado a norte pelo terreno Alto Pajeú e a sul pelo terreno Rio Capibaribe. É composto predominantemente por ortognaisses, além de sequências supracrustais geralmente migmatizadas. $\mathrm{Na}$ área de estudo, os termos ortoderivados correspondem a gnaisses de composição intermediária a ácida e rochas metamáficas associados ao Complexo Cabaceiras (idade de $2055 \mathrm{Ma}$ — Lages e Marinho 2012; Neves et al. 2015) e augen gnaisses de composição sienogranítica a monzogranítica, representados pelo Ortognaisses São Joãozinho (idade de $2109 \mathrm{Ma}$ — Lages e Marinho 2012; Neves et al. 2015) (Fig. 2). As idades-modelo $\mathrm{T}_{\mathrm{DM}}$ para essas rochas variam entre 3,3 e 2,5 Ga, indicando a presença de crosta arqueana retrabalhada (Lages et al. 2010; Lages 2012; Lages e Marinho 2012; Neves et al. 2015). Esses dados contrastam com as idades-modelo $\mathrm{T}_{\mathrm{DM}}$ obtidas para o terreno Alto Pajeú, que mostram valores característicos entre 1,0 e 2,0 Ga (Rodrigues e Brito-Neves 2008). Ocorrem ainda na área granitoides de idade caliminiana e características intraplaca associados à Suíte Carnoió (Lages et al. 2013; Brasilino et al. 2009) e leucognaisses, metapiroxenitos e rochas metamáficas atribuídas ao Complexo Sumé. As sequências supracrustais são representadas na área por granada paragnaisses do Complexo Sertânia e, em menor extensão, paragnaisses e rochas calcissilicáticas associadas ao Complexo Sumé.

O plutonismo granítico neoproterozoico no Domínio Central da Província Borborema apresenta grande diversidade, seja do ponto de vista da assinatura geoquímica, seja de sua inserção no ciclo orogenético ediacarano. Em função dessa diversidade, várias classificaçóes de cunho petrográfico, geoquímico e geocronológico foram propostas para a região (Almeida et al. 1967; Sial 1984; Ferreira et al. 1998; Santos e Medeiros 1999; Brito-Neves et al. 2000; Ferreira et al. 2004; Guimarães et al. 2004). Embora não exista uma classificação consensual, os dados geocronológicos existentes levaram Ferreira et al. (2004) a definir três eventos principais de magmatismo nesse domínio. O primeiro evento ocorreu entre 650 e 610 Ma e está associado a plutons de assinatura cálcio-alcalina, cálcio-alcalina de alto Ke shoshonítica. Os dois primeiros destacam-se pela presença de epidoto magmático. Esses corpos normalmente exibem foliação de baixo ângulo e são anteriores ou contemporâneos aos eventos de migmatização e ao pico metamórfico do Domínio Central 
(Guimarães et al. 2004; Neves et al. 2006). O segundo evento se deu entre 590 e 570 Ma e está representado por um volumoso magmatismo que inclui as rochas cálcio-alcalinas de alto-K associadas a K-dioritos, sienitoides potássicos peralcalinos a ultrapotássicos, em grande parte pertencentes ao syenitoid line (Ferreira et al. 2004), e sienitoides metaluminosos de alto-K. Esse magmatismo registra a transição entre a tectônica tangencial e a transcorrente/transpressiva que se desenvolveu na província (Guimarães et al. 2004). O último evento se estendeu do final do Neoproterozoico III ao início do Cambriano (545 a $512 \mathrm{Ma}$ ) e está relacionado à colocação de plutons cálcio-alcalinos com assinaturas de granitos do tipo-A e diques peralcalinos, ambos representantes do estágio pós-orogênico. $\mathrm{O}$ trabalho de Guimarães

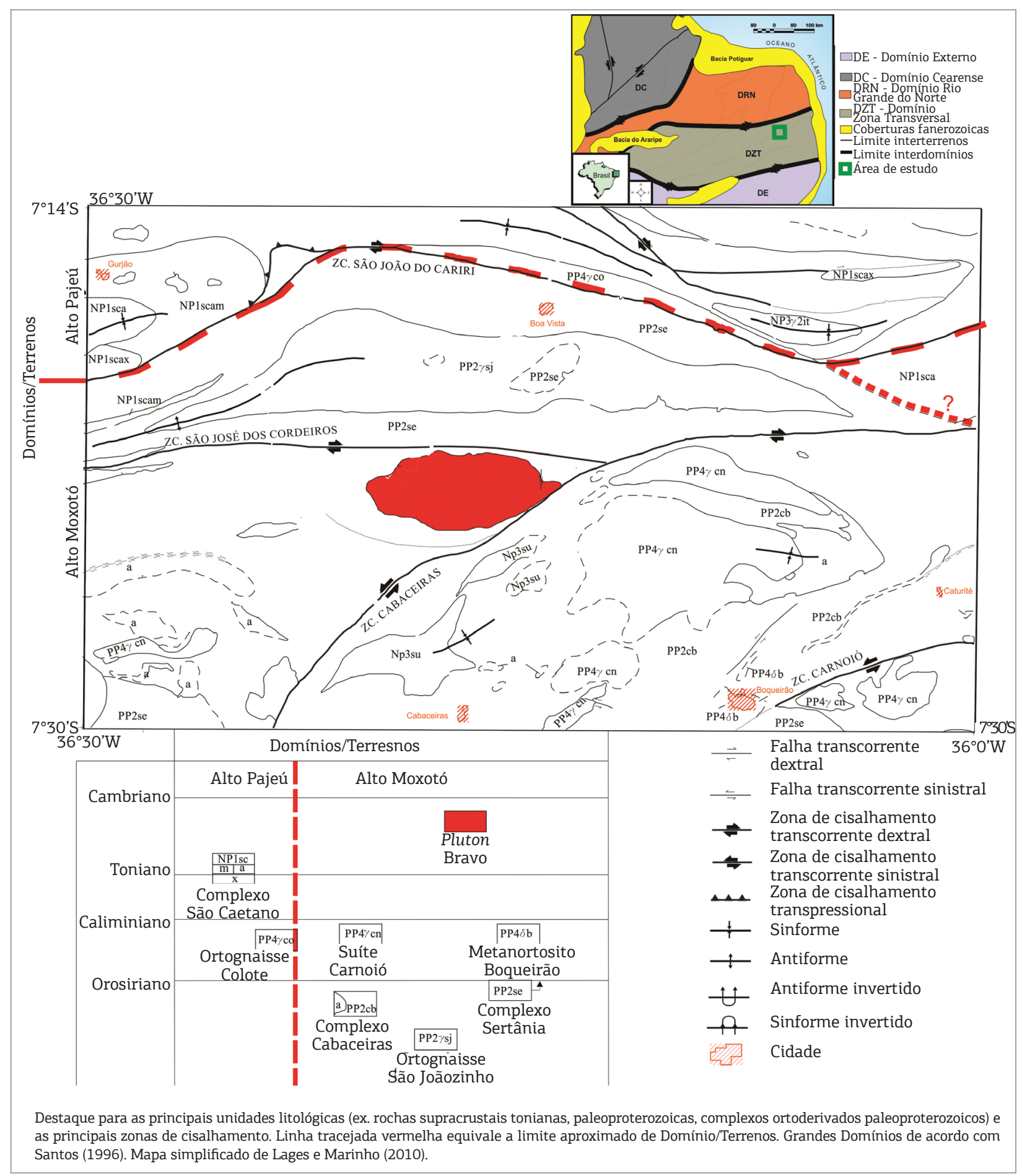

Figura 1. Contexto geotectônico do Pluton Bravo na porção central da Província Borborema. 
et al. (2004) indica um quarto evento de magmatismo, em parte coincidente aos estágios finais do segundo evento (ca. $570 \mathrm{Ma}$ ). Esse evento seria responsável pela formação de magmas com assinatura ferrosa, de afinidade anidra e reduzida e com assinaturas semelhantes a granitoides tipo-A. Esse fato contrasta com os magmas cálcio-alcalinos e shoshoníticos presentes nos eventos pretéritos. A colocação desses magmas ocorreu em sítios extensionais desenvolvidos durante a fase transcorrente no estágio pós-colisional (Almeida et al. 2002; Guimarães et al. 2004).

O magmatismo no terreno Alto Moxotó é considerado restrito, em comparação aos demais terrenos do Domínio Central (Brito Neves et al. 2000; Ferreira et al. 2004). Os corpos foram alojados em importantes zonas de cisalhamento ou próximos aos limites do terreno, o que refletiu em sua orientação geral NE-SW ou E-W. Os principais representantes correspondem a plutons cálcio-alcalinos de alto-K, cujas idades variam entre $618 \mathrm{Ma}$ (Pluton Aroeira - Neves et al. 2010) até $550 \mathrm{Ma}$ (Pluton Marinho - Brasilino et al. 2012). Estão presentes também nesse domínio os granitoides ferrosos pós-colisionais de idade ca. $570 \mathrm{Ma}$ (Plutons Queimadas e
Serra Branca - Almeida et al. 2002; Guimarães et al. 2004) e os granitoides tipo-A pós-tectônicos com idades entre 512 e $545 \mathrm{Ma}$ (Plutons Prata, Pereiro e Velho Zuza — Guimarães et al. 2004; Guimarães et al. 2005).

O Pluton Bravo, objeto deste estudo, aflora no centro-leste do Estado da Paraíba, na localidade de Bravo, município de Cabaceiras. O corpo ocorre no contexto do terreno Alto Moxotó (Fig. 1), próximo ao limite do terreno Alto Pajeú, e foi alojado em ortognaisses graníticos de alto grau metamórfico do Complexo Cabaceiras. O quimismo da rocha encaixante remete a granitos, granodioritos e tonalitos (subordinados), cálcio-alcalinos de médio K com características de arco vulcânico (Lages et al. 2009; Neves et al. 2015).

\section{ASPECTOS ESTRUTURAIS E PETROGRÁFICOS DE CAMPO}

O Pluton Bravo constitui um stock com área de aproximadamente $40 \mathrm{~km}^{2}$ com forma elipsoidal orientada

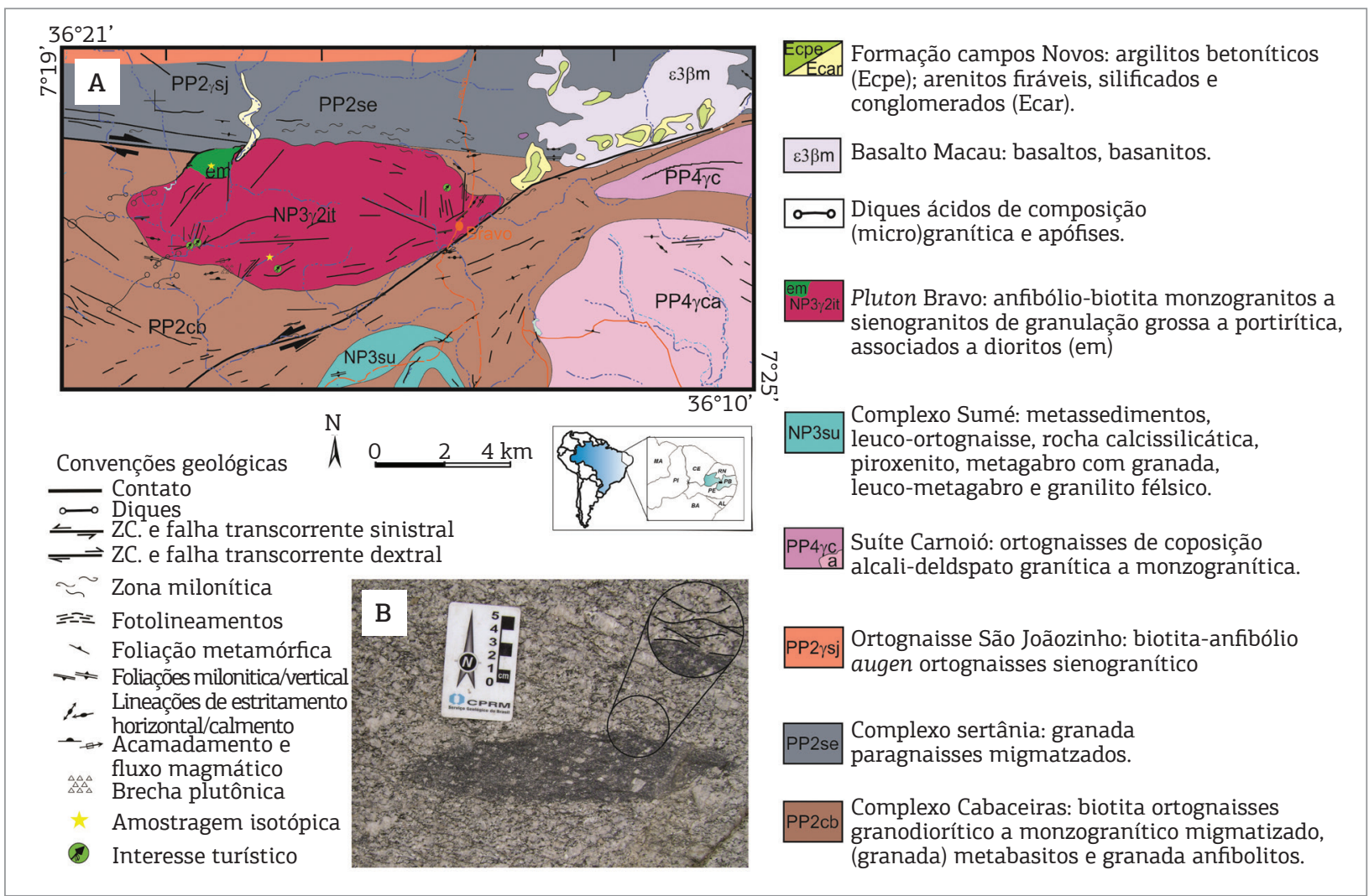

Figura 2. (A) Mapa geológico do Pluton Bravo com localização de estruturas magmáticas, deformacionais e do local de amostras coletadas para análises isotópicas. Modificado de Lages et al. (2014). (B) Enclave microgranular máfico estirado perpendicularmente à direção de tensão principal. É possível observar foliação milonítica do tipo $\mathrm{S}-\mathrm{C}$ de cinemática dextral (detalhe) e assimilação de megacristais de K-feldspato pela massa diorítica. 
segundo a direção E-W. O corpo foi posicionado em um diedro agudo formado pela junção de duas zonas de cisalhamento direcionais conjugadas (Fig. 2A), as quais possuem orientações NE-SW (Zona de Cisalhamento Cabaceiras) e E-W (Zona de Cisalhamento São José dos Cordeiros) e cinemáticas sinistral e dextral, respectivamente. $\mathrm{O}$ arranjo cinemático desses cisalhamentos indica que o pluton foi posicionado em uma zona de dilataçáo associada ao regime tectônico transcorrente. Essas estruturas foram responsáveis pelo desenvolvimento de foliações miloníticas (Fig. 2B) nas bordas do corpo que, por vezes, afetaram uma foliação magmática de borda anterior.

O stock é composto por três fácies distintas. A fácies predominante é leucocrática, definida por biotita monzogranitos a sienogranitos de coloração cinza e textura inequigranular grossa a porfirítica. Apresenta megacristais de feldspato com tamanho médio de $1,5 \mathrm{~cm}$. Essas rochas são compostas essencialmente por feldspato potássico $(17-32 \%)$, plagioclásio $(17-32 \%)$, quartzo $(22-30 \%)$, biotita $(7-15 \%)$, anfibólio (1-5\%), titanita (3\%), apatita, allanita, minerais opacos e zircão como acessórios. O plagioclásio possui zonação normal e está comumente saussuritizado. O K-feldspato microclínio é o mais abundante e quase sempre exibe textura pertítica. $\mathrm{O}$ quartzo ocorre como agregados policristalinos e mostra contatos irregulares.

A segunda fácies corresponde a anfibólio-biotita-quarzto-dioritos e monzodioritos. Possui textura equigranular e granulação fina a média. Os litotipos são compostos essencialmente por hornblenda $(30-40 \%)$, biotita $(20-25 \%)$, plagioclásio $(20-30 \%)$, quartzo $(8-10 \%)$ e K-feldspato $(5-7 \%)$. Os minerais acessórios são os mesmos observados para fácies monzogranítica. Sua maior concentraçáo ocorre próxima às bordas do pluton e chega a ter expressão cartográfica na sua porção NNW (Fig. 2). Sua ocorrência se dá na forma de pequenos corpos ou mais comumente associada a zonas de hibridização magmática. Essas zonas híbridas incluem enclaves máficos e diques imersos na fácies monzogranítica. Os enclaves possuem formas elipsoidais e em alguns locais formam enxames (Fig. 3). Os diques são mais raros e comumente mostram contatos irregulares e difusos com a fácies monzogranítica, o que sugere uma intrusão na encaixante parcialmente cristalizada. Esse caráter sin-magmático é reforçado pela presença de xenocristais de feldspato assimilados, os quais também são observados nos enclaves magmáticos (Fig. 3).

A terceira fácies foi observada na porção SSW do corpo e mais comumente sob a forma de diques aplíticos e pequenos corpos ou bolsóes na parte W do corpo. Essa fácies aplítica possui textura inequigranular fina a média e é representada por biotita monzogranitos cuja assembleia félsica é composta por plagioclásio, quartzo e K-feldspato. Biotita é o mineral máfico principal, e os minerais opacos e zircão são os acessórios.

$\mathrm{Na}$ borda sul do pluton é possível observar brechas magmáticas definidas por uma matriz fina de composição predominantemente granodiorítica a diorítica e fragmentos compostos por autólitos de granitoides e dioritos, além de xenólitos de gnaisses encaixantes, principalmente do Complexo Cabaceiras (Fig. 4A). Trata-se de um processo de fraturamento e assimilação de fragmentos da rocha encaixante nas bordas do magma em ascensão. Em alguns locais a brecha apresenta caráter cataclástico a milonítico, indicando processos deformacionais superimpostos (Fig. 4B).

Em geral, a trama observada no pluton é isotrópica no centro do corpo, enquanto nas bordas observam-se tramas protomiloníticas associadas às zonas de cisalhamento transcorrentes (Figs. 2 e 5A). O acervo das estruturas compreende foliaçóes do tipo $\mathrm{S} / \mathrm{C}$ dextrais e sinistrais, por vezes afetando enclaves, xenólitos e diques. Na porção SSW do corpo observam-se foliaçôes C/C' de caráter dextral. Microestruturas comuns são: formação de extinção ondulante no quartzo, texturas manto-núcleo nos feldspatos (Fig. 5B) e recristalização nos cristais de quartzo.

Em todo o pluton é comum a ocorrência de enclaves magmáticos e cristais de feldspatos (raros augens) orientados segundo a deformação, que denota o fluxo magmático concomitante ao cisalhamento. Os enclaves ocorrem alongados entre E-W e ESE-WNW, o que mostra paralelismo com a direção de estiramento $\left(\sigma_{3}\right)$ prevista para as zonas de cisalhamento transcorrentes (Fig. 2B).

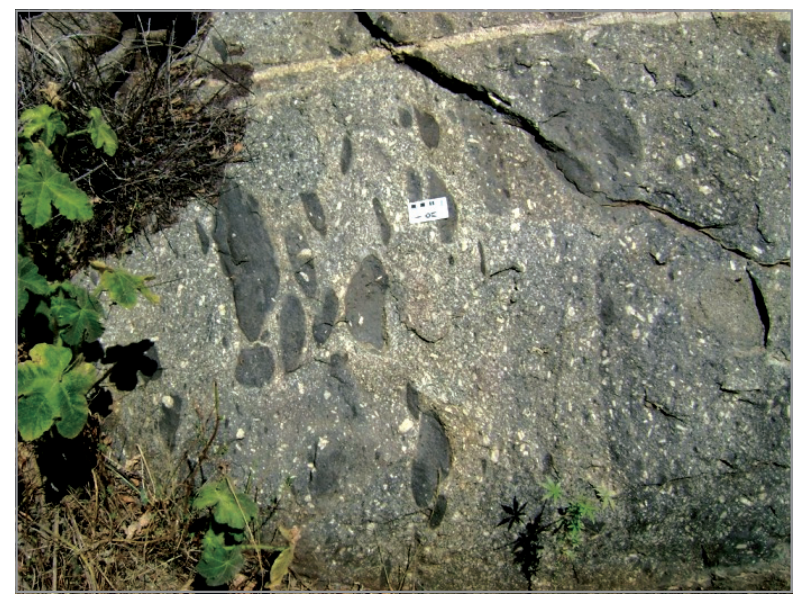

Figura 3. Corredor de enclaves máficos em granitoides do Pluton Bravo, sendo possível observar a assimilação de megacristais de K-feldspato da fácies félsica pelos enclaves dioríticos. 


\section{RESULTADOS}

\section{Litoquímica}

Foram analisadas 11 amostras do Pluton Bravo, das quais 8 compreendem a fácies monzogranítica porfirítica, 2, a fácies diorítica, e 1, a fácies aplítica. Embora o número de amostras seja reduzido para os dioritos e o aplito, estes serão apresentados com a finalidade de compará-los aos monzogranitos porfiríticos. Os resultados obtidos para os elementos maiores, traços e terras raras estão apresentados na Tabela 1 e foram parcialmente apresentados em Lages et al. (2011) e Lages et al. (2014).
A fácies monzogranítica a sienogranítica porfirítica é composta por rochas félsicas $\left(72,7-68,4 \% \mathrm{de} \mathrm{SiO}_{2}\right)$, caracterizadas como metaluminosas a levemente peraluminosas, com $0,95 \leq(\mathrm{A} / \mathrm{CNK}) \leq 1$ (Fig. 6A). A fácies mais evoluída é a aplítica, com $\mathrm{SiO}_{2}=73,5 \%$. A fácies diorítica corresponde a rochas intermediárias $\left(-55 \%\right.$ de $\left.\mathrm{SiO}_{2}\right)$ e metaluminosas. Todas as fácies exibem rochas com alto conteúdo de álcalis e enriquecimento em $\mathrm{K}$, com razão $\mathrm{K} 2 \mathrm{O} / \mathrm{Na}_{2} \mathrm{O}>1$ e possuem elevado valor de $\mathrm{Fe} \#\left(\mathrm{FeO} / \mathrm{FeO}_{t}+\mathrm{MgO}\right)$, entre 0,86 e 0,94. Os dioritos destacam-se pelo conteúdo mais elevado em Fe. De acordo com os critérios de Middlemost (1997), as rochas estudadas enquadram-se como transalcalinas, exceto a fácies aplítica. As fácies sieno/monzogranítica, aplitíca e
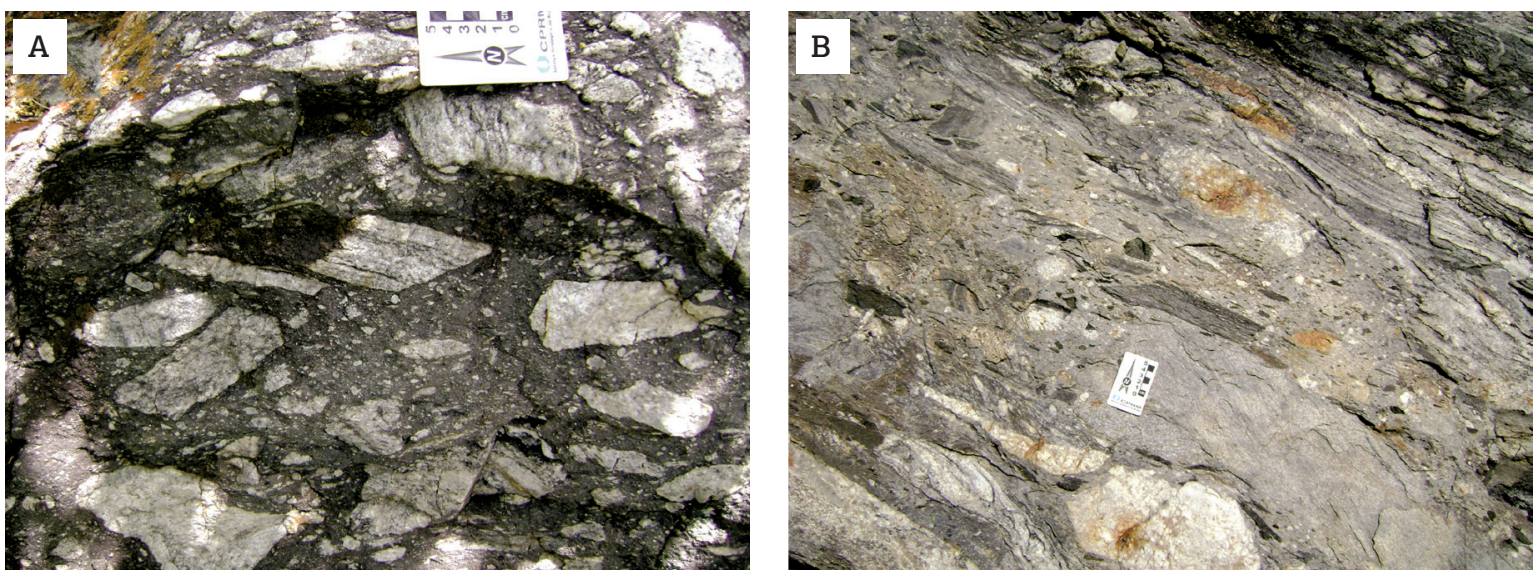

Figura 4. Aspectos das brechas magmáticas próximas ao contato das rochas graníticas do Pluton Bravo e o ortognaisse encaixante. (A) Brecha magmática com matriz diorítica portando xenólitos do Complexo Cabaceiras. (B) Brecha magmática exibe fragmentos (autólitos e xenólitos) orientandos e com textura protocataclástica.
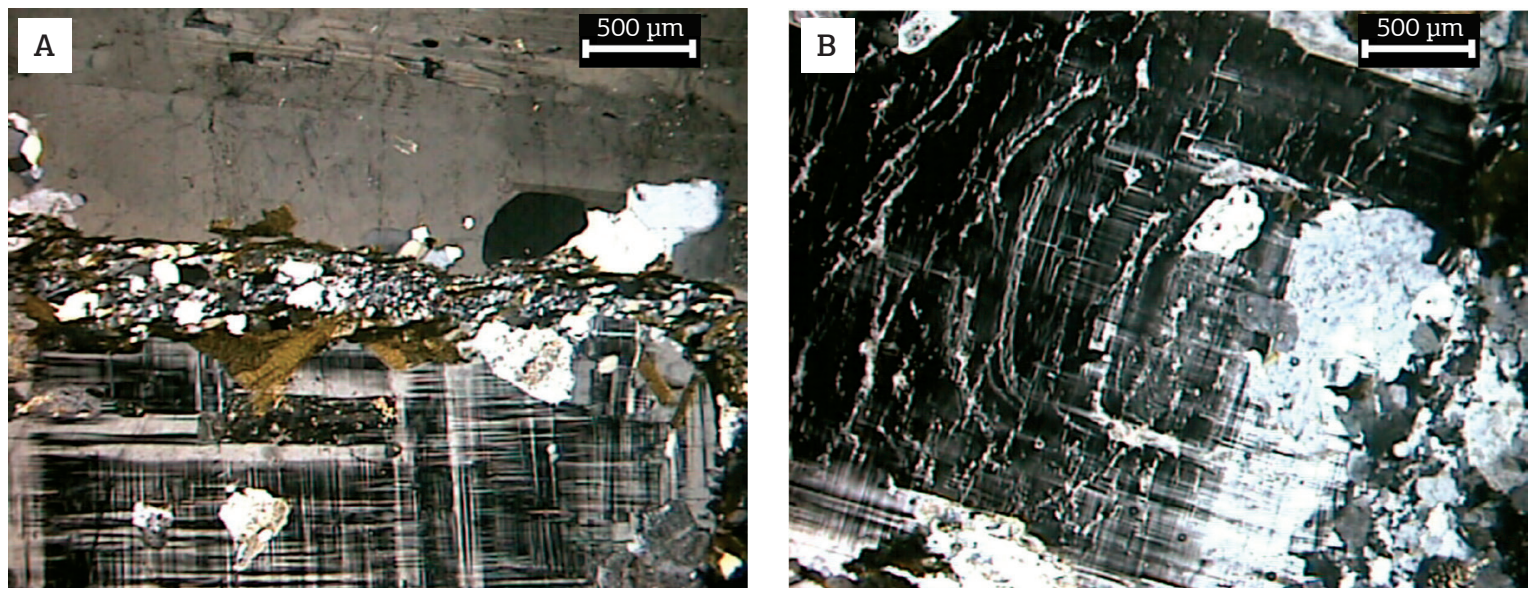

Figura 5. Fotomicrografia do granito porfurítico mostrando: (A) matriz milonítica quartzo-feldspática desenvolvida entre dois megacristais de feldspatos. (B) Microclínio hipidiomórfico zonado com textura Mortar na borda direita. 
Idade e Petrologia do Pluton Bravo, Nordeste do Brasil

Tabela 1. Composição química de elementos maiores (\% em peso) e traços (ppm) para amostras do Pluton Bravo.

\begin{tabular}{|c|c|c|c|c|c|c|c|c|c|c|c|}
\hline \multirow{2}{*}{ Amostra } & \multicolumn{8}{|c|}{ Fácies Monzo/Sienogranítica porfiríticos } & \multirow{2}{*}{$\begin{array}{c}\begin{array}{c}\text { Fácies } \\
\text { aplítica }\end{array} \\
\text { GL-474 }\end{array}$} & \multicolumn{2}{|c|}{ Fácies diorítica } \\
\hline & GL-196 & GL-199 & GL-202B & GL-472 & GL-477 & GL-482 & GL-483 & GL-484 & & GL-202A & GL-473 \\
\hline $\mathrm{SiO}_{2}$ & 71,21 & 68,42 & 70,6 & 69,52 & 70,02 & 69,42 & 70,64 & 72,77 & 73,53 & 55,11 & 55,94 \\
\hline $\mathrm{TiO}_{2}$ & 0,37 & 0,71 & 0,48 & 0,51 & 0,47 & 0,55 & 0,43 & 0,23 & 0,23 & 1,68 & 1,64 \\
\hline $\mathrm{Al}_{2} \mathrm{O}_{3}$ & 13,89 & 14,09 & 13,48 & 13,75 & 13,91 & 14,11 & 13,56 & 13,33 & 13,42 & 14,74 & 14,36 \\
\hline $\mathrm{Fe}_{2} \mathrm{O}_{3 \mathrm{t}}$ & 3,36 & 4,68 & 4,23 & 4,01 & 3,74 & 4,14 & 3,86 & 2,58 & 2,38 & 12,61 & 12,26 \\
\hline $\mathrm{MnO}$ & 0,05 & 0,07 & 0,05 & 0,05 & 0,05 & 0,05 & 0,05 & 0,03 & 0,03 & 0,17 & 0,16 \\
\hline $\mathrm{MgO}$ & 0,39 & 0,67 & 0,48 & 0,49 & 0,46 & 0,51 & 0,43 & 0,16 & 0,38 & 1,72 & 1,71 \\
\hline $\mathrm{CaO}$ & 1,5 & 2,17 & 1,67 & 1,85 & 1,69 & 1,79 & 1,6 & 1,16 & 1,68 & 4,64 & 4,51 \\
\hline $\mathrm{Na}_{2} \mathrm{O}$ & 3,29 & 3,23 & 2,91 & 3,09 & 3,06 & 3,1 & 3,01 & 3,02 & 3,37 & 3,48 & 3,32 \\
\hline $\mathrm{K}_{2} \mathrm{O}$ & 5,28 & 5,14 & 5,4 & 5,32 & 5,49 & 5,4 & 5,18 & 5,72 & 4,05 & 4,06 & 4,23 \\
\hline $\mathrm{P}_{2} \mathrm{O}_{5}$ & 0,12 & 0,27 & 0,15 & 0,19 & 0,15 & 0,18 & 0,15 & 0,06 & 0,09 & 0,82 & 0,79 \\
\hline $\mathrm{PF}$ & 0,3 & 0,2 & 0,3 & 0,9 & 0,6 & 0,4 & 0,8 & 0,7 & 0,7 & 0,4 & 0,5 \\
\hline Soma & 99,76 & 99,65 & 99,75 & 99,67 & 99,65 & 99,67 & 99,69 & 99,77 & 99,85 & 99,42 & 99,41 \\
\hline $\mathrm{A} / \mathrm{CNK}^{*}$ & 1,00 & 0,95 & 0,98 & 0,97 & 0,99 & 0,99 & 1,01 & 1,00 & 1,03 & 0,79 & 0,78 \\
\hline $\mathrm{K}_{2} \mathrm{O} / \mathrm{Na}_{2} \mathrm{O}$ & 1,6 & 1,59 & 1,86 & 1,72 & 1,79 & 1,74 & 1,72 & 1,89 & 1,2 & 1,16 & 1,27 \\
\hline$\# \mathrm{Fe}^{* *}$ & 0,89 & 0,87 & 0,89 & 0,89 & 0,89 & 0,89 & 0,89 & 0,94 & 0,86 & 0,87 & 0,87 \\
\hline $\mathrm{Ni}$ & 2,2 & 3,6 & 10 & 2,8 & 2,6 & 2,8 & 2,2 & 1,2 & 2,9 & 1,4 & 3,4 \\
\hline Co & 3,5 & 6,3 & 5,5 & 4,7 & 4,6 & 5,1 & 4,5 & 1,9 & 3,2 & 20 & 18,9 \\
\hline V & 12 & 25 & 17 & 26 & 21 & 24 & 19 & $<8$ & 17 & 69 & 68 \\
\hline $\mathrm{Cu}$ & 2,9 & 12,5 & 5 & 8,1 & 7,8 & 6,8 & 5 & 3 & 5,7 & 33,4 & 28,8 \\
\hline $\mathrm{Pb}$ & 13,4 & 14,4 & 14,7 & 13 & 13,6 & 21,3 & 14,6 & 13,8 & 11,6 & 14,5 & 12,1 \\
\hline $\mathrm{Zn}$ & 73 & 81 & 75 & 74 & 73 & 73 & 73 & 56 & 46 & 129 & 126 \\
\hline $\mathrm{Rb}$ & 195,9 & 190,3 & 168,3 & 183,5 & 178,2 & 184,2 & 203,9 & 190,2 & 149,2 & 129,6 & 129,2 \\
\hline Cs & 2 & 1,5 & 1,2 & 1,6 & 1,3 & 1,4 & 1,5 & 0,9 & 0,6 & 0,7 & 0,6 \\
\hline $\mathrm{Ba}$ & 858 & 1135 & 1028 & 1149 & 1152 & 1204 & 1115 & 649 & 786 & 2013 & 1900 \\
\hline $\mathrm{Sr}$ & 133,5 & 202,5 & 157,5 & 181,1 & 172,9 & 190,1 & 166,1 & 102,1 & 168,6 & 378,4 & 384,4 \\
\hline $\mathrm{Ga}$ & 23,1 & 24,1 & 20,2 & 21,7 & 22 & 24 & 24,3 & 23,5 & 23,4 & 27,3 & 26,6 \\
\hline $\mathrm{Ta}$ & 1,4 & 1,8 & 1,4 & 1,6 & 1,3 & 1,8 & 2,1 & 0,7 & 0,4 & 2,4 & 2,1 \\
\hline $\mathrm{Nb}$ & 24,8 & 31,9 & 26,9 & 27,8 & 25,7 & 28,9 & 28,9 & 17,6 & 18,5 & 55 & 49,2 \\
\hline $\mathrm{Hf}$ & 10,7 & 14,7 & 11,9 & 13,1 & 13,2 & 13,9 & 13 & 9,2 & 5,1 & 28,7 & 25,7 \\
\hline $\mathrm{Zr}$ & 428,5 & 593,6 & 452,9 & 463,7 & 504,5 & 512 & 498,1 & 322,3 & 164,6 & 1248,3 & 1134,1 \\
\hline Y & 43,7 & 57,3 & 56,2 & 58,9 & 56,3 & 64,6 & 63,8 & 43,1 & 18,9 & 91,1 & 86,4 \\
\hline Th & 44,5 & 39 & 43,8 & 40,1 & 45,2 & 49 & 51,4 & 54,1 & 21,4 & 17,5 & 18,9 \\
\hline $\mathrm{U}$ & 5,6 & 3,8 & 2,8 & 3,3 & 3,2 & 3,1 & 4,4 & 5,4 & 2,6 & 2,3 & 2,1 \\
\hline $\mathrm{La}$ & 104,6 & 121,6 & 125,8 & 133 & 135,5 & 139,3 & 135,3 & 110,4 & 31,1 & 145,9 & 138,3 \\
\hline $\mathrm{Ce}$ & 210,8 & 238,8 & 241,7 & 259,5 & 271,1 & 278,3 & 266,7 & 220,8 & 64,6 & 304,3 & 286,4 \\
\hline
\end{tabular}


Tabela 1. Continuação.

\begin{tabular}{|c|c|c|c|c|c|c|c|c|c|c|c|}
\hline \multirow{2}{*}{ Amostra } & \multicolumn{8}{|c|}{ Fácies Monzo/Sienogranítica porfiríticos } & \multirow{2}{*}{$\begin{array}{c}\begin{array}{c}\text { Fácies } \\
\text { aplítica }\end{array} \\
\text { GL-474 }\end{array}$} & \multicolumn{2}{|c|}{ Fácies diorítica } \\
\hline & GL-196 & GL-199 & GL-202B & GL-472 & GL-477 & GL-482 & GL-483 & GL-484 & & GL-202A & GL-473 \\
\hline $\operatorname{Pr}$ & 23,14 & 26,39 & 27,82 & 28,26 & 29,56 & 30,58 & 29,25 & 24,4 & 7,46 & 35,95 & 33,66 \\
\hline $\mathrm{Nd}$ & 84,6 & 95,6 & 102,7 & 101,5 & 109,1 & 112 & 108,4 & 86,6 & 28,7 & 141,6 & 134 \\
\hline Sm & 13,97 & 15,6 & 16,67 & 15,63 & 16,4 & 17,71 & 17,21 & 13,51 & 5,2 & 23,23 & 22,31 \\
\hline $\mathrm{Eu}$ & 1,28 & 1,76 & 1,62 & 1,5 & 1,55 & 1,74 & 1,61 & 1,16 & 0,99 & 4,57 & 4,18 \\
\hline Gd & 11,34 & 13,21 & 12,64 & 12,72 & 13,43 & 14,6 & 14,49 & 10,67 & 4,36 & 20,03 & 19,14 \\
\hline $\mathrm{Tb}$ & 1,68 & 2,01 & 2,05 & 1,92 & 1,95 & 2,21 & 2,2 & 1,56 & 0,7 & 3,05 & 2,87 \\
\hline Dy & 9,06 & 10,87 & 11,31 & 10,34 & 10,81 & 12,16 & 12,14 & 8,68 & 3,45 & 18,04 & 15,85 \\
\hline Ho & 1,7 & 2,15 & 2,12 & 2,05 & 2,01 & 2,31 & 2,26 & 1,6 & 0,66 & 3,41 & 3,09 \\
\hline $\mathrm{Er}$ & 4,57 & 5,87 & 5,77 & 5,71 & 5,34 & 6,47 & 6,49 & 4,31 & 1,73 & 9,58 & 8,61 \\
\hline $\mathrm{Tm}$ & 0,72 & 0,94 & 0,86 & 0,9 & 0,83 & 0,99 & 0,96 & 0,68 & 0,25 & 1,46 & 1,31 \\
\hline $\mathrm{Yb}$ & 4,35 & 5,81 & 4,93 & 5,21 & 4,69 & 5,73 & 5,77 & 4,04 & 1,4 & 9,1 & 7,92 \\
\hline $\mathrm{Lu}$ & 0,62 & 0,87 & 0,69 & 0,74 & 0,67 & 0,81 & 0,81 & 0,58 & 0,21 & 1,35 & 1,17 \\
\hline ¿ETR & 472,43 & 541,48 & 556,68 & 578,98 & 602,94 & 624,91 & 603,59 & 488,99 & 150,81 & 721,57 & 678,81 \\
\hline
\end{tabular}

${ }^{*} \mathrm{~A} / \mathrm{CNK}\left(\mathrm{Al}_{2} \mathrm{O}_{3} /\left(\mathrm{CaO}+\mathrm{Na}_{2} \mathrm{O}+\mathrm{K}_{2} \mathrm{O}\right)(\%) ;{ }^{* *} \mathrm{He}(\mathrm{FeO} /(\mathrm{FeO}+\mathrm{MgO})(\%)\right.$.

diorítica estão inseridas na série ferrosa de Frost et al. (2001) e exibem assinaturas álcali-cálcica, cálcioalcalina e alcalina, respectivamente, considerando os campos propostos por Frost et al. (2001) (Figs. 6B e 6C). Embora o número de amostras seja reduzido, observa-se que as fácies monzogranítica e diorítica apresentam comportamentos diferentes nos diagramas químicos, o que indica a participação de magmas com origens distintas na formaçáo do pluton.

Ao analisar os elementos traços, a fácies monzogranítica exibe teores baixos a médios de Sr (102 a 202 ppm) e de Rb (149 a 203 ppm) e moderados a altos de Ba (649 a $1.204 \mathrm{ppm}$ ), quando comparada a granitos tipo-A (e.g. Whalen et al. 1987; Eby 1990). As razóes (Y/Nb) variam entre 1,7 e 2,4. Os dioritos exibem altos teores de $\mathrm{Ba}(1.900$ a $2.013 \mathrm{ppm}$ ), Nb (49 a $55 \mathrm{ppm}), \mathrm{Y}$ (86 a 91 ppm), $\mathrm{TiO}_{2}$ $(\sim$ 1,68\%), muito altos de $\mathrm{Zr}(1.134$ a 1.268 ppm) e razão $(\mathrm{Y} / \mathrm{Nb})$ - 1,7. O espectro multielementar normalizado por Thompson (1982) (Fig. 7A) mostra, nos monzogranitos, o fracionamento dado pela razão dos elementos LILE/ HFSE, com anomalias positivas em The La, altos valores normalizados de $\mathrm{Nb}$ e Ta, fortes anomalias negativas em $\mathrm{P}$, Ti e anomalias menos pronunciada em Sr. Os dioritos distinguem-se pela presença de anomalias positivas mais pronunciadas em $\mathrm{Zr}$ e Hf e por um pico menos pronunciado de elementos móveis Th, $\mathrm{K}$ e Rb. Essas características são comuns a granitos tipo-A (Whalen et al. 1987; Eby 1990).
A fácies monzogranítica possui um conteúdo total de elementos terras-raras ( $\Sigma E T R$ ) inferior a fácies diorítica, com valores entre 624 e 472 ppm e 724 e 678 ppm, respectivamente, e $\Sigma E T R ~-151$ ppm para a fácies aplítica. O diagrama de ETR, normalizado pelo condrito (Boynton 1984) (Fig. 7B), indica razóes $(\mathrm{La} / \mathrm{Yb})_{\mathrm{N}}$ entre 19 e 14, evidenciando um segmento plano com altos teores de ETR pesados, bem como uma forte anomalia negativa de Eu para os monzogranitos e o aplito, com $\left(\mathrm{Eu} / \mathrm{Eu}^{*}\right)_{\mathrm{N}}$ entre 0,37 e 0,31 . Os dioritos são enriquecidos em ETR pesados, com razóes $(\mathrm{La} / \mathrm{Yb})_{\mathrm{N}}<10$, e anomalias negativas de Eu menos pronunciadas $\left(\mathrm{Eu}_{\mathrm{N}} / \mathrm{Eu}_{\mathrm{N}}{ }_{\mathrm{N}}-0,63\right)$. Os padróes normalizados para os elementos terras-raras também são sugestivos de rochas compatíveis com granitos tipo-A (Whalen et al. 1987; Eby 1990).

$\mathrm{O}$ trend paralelo ao lado $\left(\mathrm{Na}_{2} \mathrm{O}+\mathrm{K}_{2} \mathrm{O}\right)-\mathrm{FeOt}$ do diagrama AFM (Irvine e Baragar 1971) para as amostras dos sieno/monzogranitos e enclaves dioríticos estudados evidencia um comportamento comum a granitos do tipo-A (Fig. 8A) e reflete cristalização sob baixa $\mathrm{fO}_{2}$ (Sial 1989; Almeida et al. 2002). No diagrama discriminante de ambientes tectônicos de Pearce et al. (1996), as amostras plotam no campo de granitos pós-tectônicos/intraplaca (Fig. 8B). No diagrama de Eby (1992) para granitos tipo-A, as amostras do granitoide plotam no campo A2, que é consistente com derivação a partir de fontes crustais (Fig. 8C). 
A

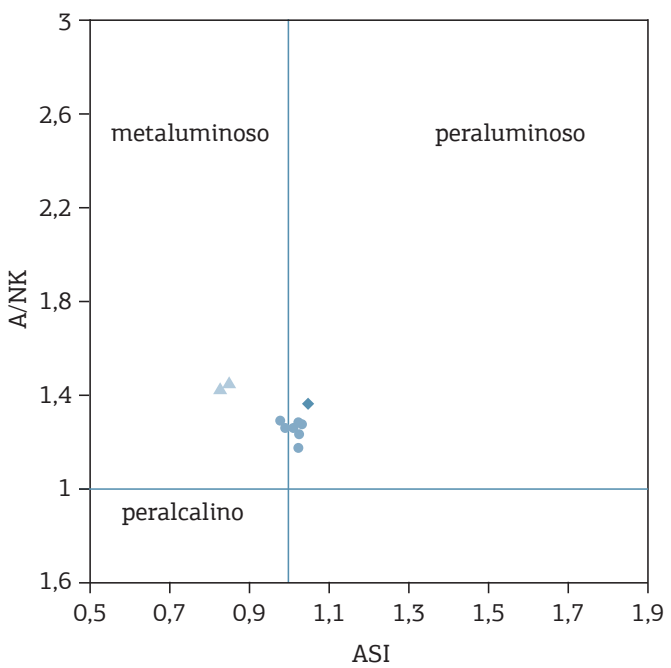

$\mathrm{B}$

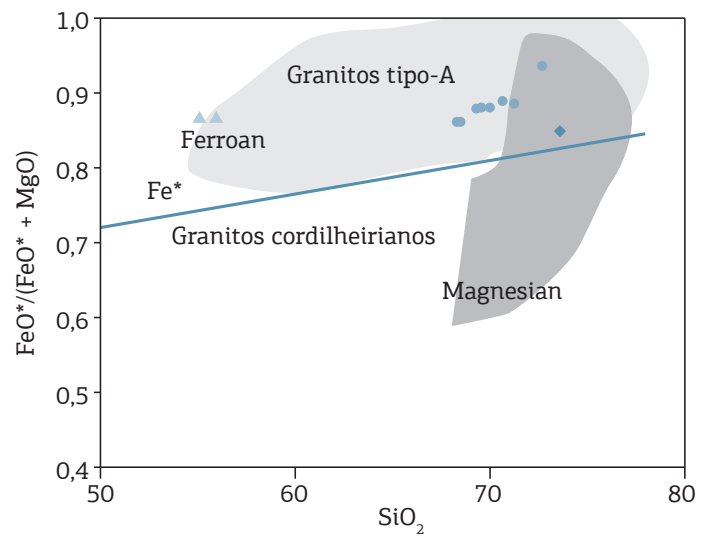

C

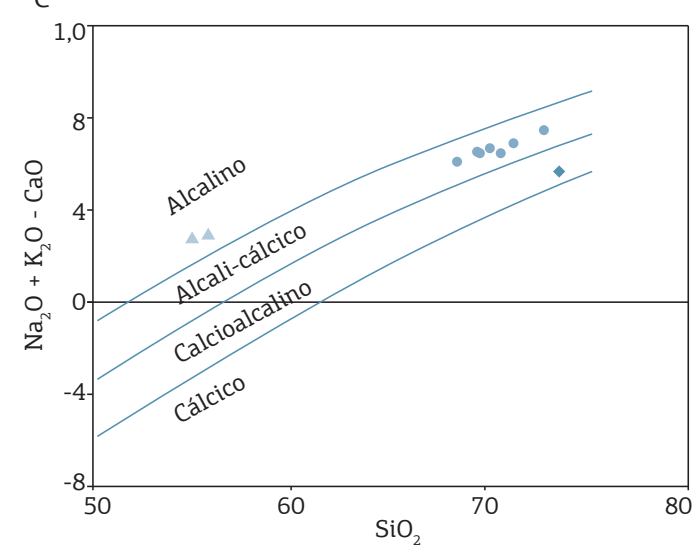

Figura 6. Diagramas de classificação para amostras do Pluton Bravo (fácies monzogranitica = círculo, diorítica = triângulo e aplítica = losango). (A) Diagrama A/CNK x A/NK de Maniar e Picoli (1989). (B) Diagrama de classificação entre granitos ferrosos e magnesianos (Frost et al. 2001). (C) Diagrama do índice MALI versus sílica (Frost et al. 2001) para as amostras estudadas, mostrando o controle dos minerais ígneos como feldspatos e quartzo fracionados e extraídos da fusão.

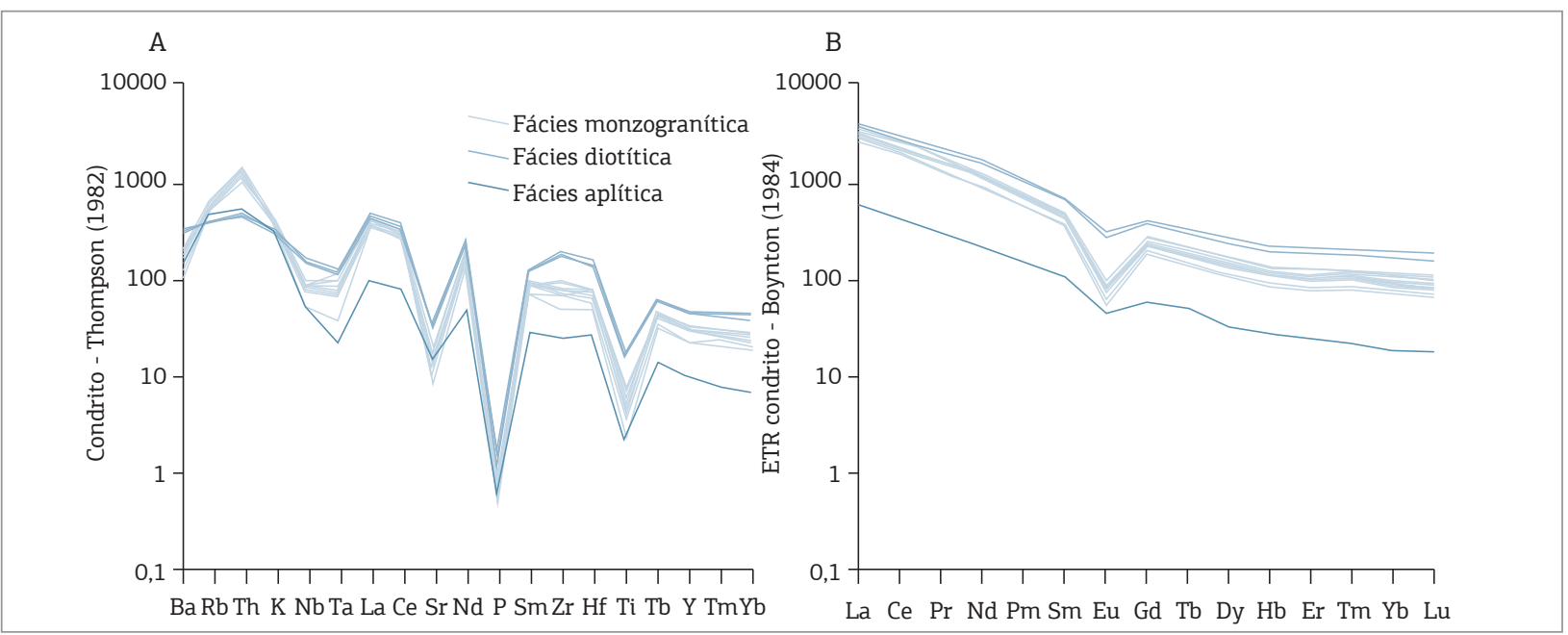

Figura 7. (A) Diagrama multielementar normalizado, segundo Thompson (1982). (B) Espectro de ETR normalizado, segundo Boynton (1984). 


\section{Química Mineral e Geotermobarometria}

Foram realizadas 11 análises em plagioclásio e 8 em anfibólio na fácies sienogranítica porfirítica (Tab. 2). Essas análises foram realizadas nos contatos entre os minerais em equilíbrio, permitindo aplicar geotermobarômetros específicos para os pares correspondentes.

Os anfibólios possuem fórmula estrutural calculada com base em 23 oxigênios, enquanto o conteúdo de $\mathrm{Fe}^{3+}$ foi estimado com base em Schumacher (1997) utilizando-se uma estimativa máxima de 13 cátions excluindo ( $\mathrm{Ca}, \mathrm{Na}$ e K) que se mostrou precisa para anfibólios cálcicos (Gualda e
Vlach 2005). Segundo a classificação de Leake et al. (1997), baseada no conteúdo de $\mathrm{Si}$ e pela razáo $\mathrm{Mg} /\left(\mathrm{Fe}^{+2}+\mathrm{Mg}\right)$ para uma relação $\mathrm{Ca}>1,50 ;(\mathrm{Na}+\mathrm{K})>0,50 ; \mathrm{Ti}<0,50$, os anfibólios correspondem a ferro edenitas (C1-3, C1-4 e C3-2), ferro pargasitas (C2-1 e C2-2) e hastingsitas (C3-1, C4-3 e C4-4) (Fig. 9A). Os plagioclásios, com fórmula calculada para 32 oxigênios, apresentam composição oligoclásica com teores de anortita entre 14 e 18\% (Fig. 9B).

As estimativas de pressão de cristalizaçáo do Pluton Bravo foram realizadas com base no conteúdo de $\mathrm{Al}^{t}$ de hornblendas, utilizando as recalibrações discutidas na formulação
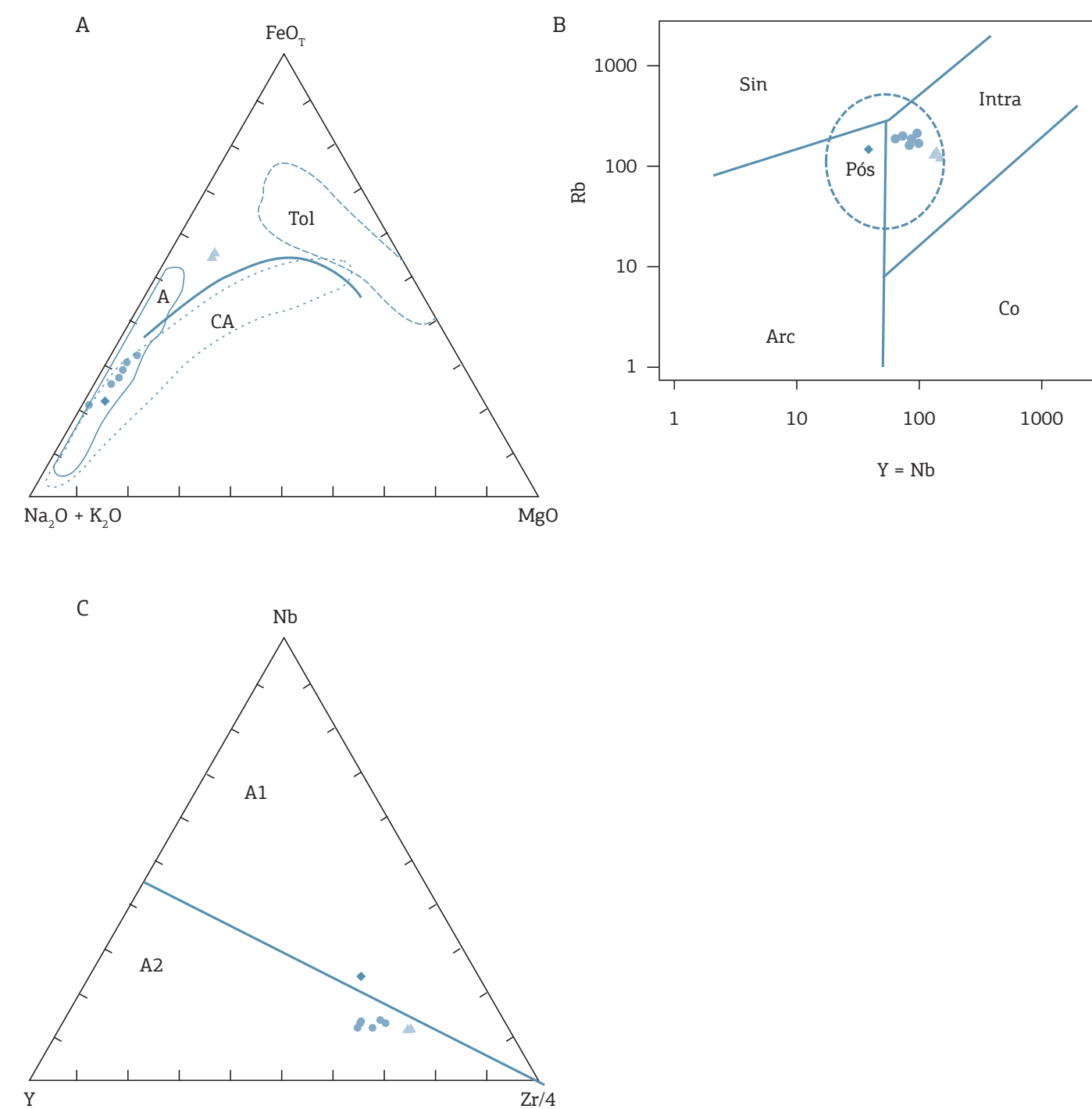

Tol: série toleítica; CA: série cálcio-alcalina; A: magmatismo tipo-A; Sin: sin-colisional; Arc: arco vulcânico; Intra: intraplaca; Pós: pós-colisional; Co: cadeia oceânica.

A1: Granitos tipo-A derivados de fontes mantélicas; A2: Granitos tipo-A derivados de fontes crustais ou underplating. Os símbolos são os mesmos da Figura 6 .

Figura 8. (A) Diagrama AFM (Irvine e Baragar 1971) para as amostras do Pluton Bravo. (B) Diagrama discriminante de ambiente tectônico de Pearce et al. (1996) mostrando que as amostras do Pluton Bravo plotam no campo de granitos pós-colisionais/intraplaca. (C) Diagrama Nb-Y-Zr/4 para as amostras estudadas (Eby 1992). 
empírica de Hammarstrom e Zen (1986) e nas formulações experimentais de Schmidt (1992) e Johnson e Rutherford (1989). O geotermobarômetro integrado de Anderson e Smith (1995), que incorpora a temperatura e considera a fugacidade de oxigênio como outras variáveis, não pode ser aplicado para essas rochas porque os anfibólios extrapolam os valores recomendados (calibrados para rochas cristalizadas em ambiente de alta a média $\left.\mathrm{fO}_{2}\right)$ de $\mathrm{Fe}_{\mathrm{t}} /\left(\mathrm{Fe}_{\mathrm{t}}+\mathrm{Mg}\right)>$ 0,81 (recomendado: 0,40-0,65) e plagioclásio com teor de $A_{n}<21$ (recomendado: $25-35$ ). Os resultados indicaram pressões estimadas entre 7,4 e 5,4 ( \pm 3 ) Kbar para primeira, 7,7 e 5,8 ( \pm 0,6) Kbar para a segunda e 6,0 e 4,4 ( $\pm 0,5)$ Kbar para a última calibração (média $=5,1 \mathrm{Kbar}$ ). Adotou-se a última calibração por esta ser experimental com regressão linear $r^{2}=0,99$, possuir o menor erro associado $( \pm 0,5) \mathrm{Kbar}$ (Johnson e Rutherford 1989) e ter sido integrada no geotermobarômetro de Anderson e Smith (1995). Considerando uma densidade da crosta entre 2,65 e 2,8 g/ $\mathrm{cm}^{3}$ (Best 2008), essas pressões indicariam uma colocação entre 13 e 21 km de profundidade.

Tabela 2. Dados de química mineral de amostra de sienogranito obtidos por microssonda eletrônica (WDS).

\begin{tabular}{|c|c|c|c|c|c|c|c|c|c|c|c|c|c|c|c|c|c|c|c|}
\hline \multirow{2}{*}{$\begin{array}{l}\text { Mineral } \\
\text { Análise }\end{array}$} & \multicolumn{11}{|c|}{ Plagioclásio } & \multicolumn{8}{|c|}{ Hornblenda } \\
\hline & C1-1 & C1-2 & C1-5 & C1-6 & C1-7 & C2-3 & C2-4 & C3-3 & C3-4 & C4-1 & C4-2 & C1-3 & C1-4 & C2-1 & C2-2 & C3-1 & C3-2 & C4-3 & C4-4 \\
\hline $\mathrm{SiO}_{2}$ & 64,48 & 64,04 & 65,55 & 65,25 & 65,23 & 65,4 & 64,9 & 63,91 & 65,29 & 63,53 & 65,14 & 41,89 & 39,52 & 40,03 & 41,33 & 40,88 & 41,09 & 39,64 & 39,46 \\
\hline $\mathrm{Al}_{2} \mathrm{O}_{3}$ & 21,81 & 22,46 & 22,51 & 21,86 & 22,16 & 22,44 & 22,3 & 22,09 & 22,57 & 21,7 & 22,43 & 9,94 & 9,77 & 11,6 & 10,8 & 10,45 & 9,98 & 12,08 & 11,36 \\
\hline $\mathrm{TiO}_{2}$ & 0 & 0 & 0,01 & 0 & 0 & 0 & 0,03 & 0,04 & 0 & 0,04 & 0,01 & 1,34 & 1,2 & 0,6 & 0,61 & 1,82 & 2,27 & 0,43 & 0,58 \\
\hline $\mathrm{MgO}$ & 0,01 & 0 & 0,01 & 0,02 & 0,01 & 0 & 0 & 0,01 & 0 & 0 & 0,03 & 3,27 & 3,21 & 3,1 & 2,95 & 3,35 & 3,67 & 2,8 & 2,79 \\
\hline $\mathrm{FeO}$ & 0,11 & 0,06 & 0,07 & 0,11 & 0 & 0,08 & 0,08 & 0,08 & 0,08 & 0,15 & 0,14 & 26,71 & 25,33 & 26,83 & 26,28 & 27,31 & 25,99 & 28,14 & 29,15 \\
\hline $\mathrm{Na}_{2} \mathrm{O}$ & 8,69 & 8,31 & 8,3 & 8,72 & 8,63 & 8,21 & 8,08 & 8,19 & 8,56 & 7,98 & 8,29 & 1,06 & 0,9 & 1,16 & 0,79 & 0,94 & 1,29 & 1,25 & 1,09 \\
\hline $\mathrm{K}_{2} \mathrm{O}$ & 0,1 & 0,17 & 0,25 & 0,13 & 0,08 & 0,12 & 0,18 & 0,14 & 0,13 & 0,24 & 0,15 & 1,51 & 1,47 & 1,79 & 1,73 & 1,85 & 1,66 & 1,91 & 1,72 \\
\hline $\mathrm{CaO}$ & 2,74 & 3,43 & 3,23 & 2,84 & 2,95 & 3,34 & 3,6 & 3,45 & 3,41 & 2,92 & 3,36 & 11,31 & 13,44 & 11,31 & 11,36 & 10,38 & 10,97 & 11,22 & 11,18 \\
\hline $\mathrm{MnO}$ & 0 & 0 & 0,06 & 0 & 0 & 0 & 0 & 0,03 & 0 & 0,01 & 0,03 & 0,66 & 0,61 & 0,6 & 0,51 & 0,69 & 0,56 & 0,64 & 0,61 \\
\hline $\mathrm{F}$ & 0 & 0 & 0,03 & 0,05 & 0,06 & 0,03 & 0,05 & 0,07 & 0,15 & 0,08 & 0,02 & 0,25 & 0,44 & 0,17 & 0,34 & 0 & 0,49 & 0,69 & 0,52 \\
\hline $\mathrm{Cl}$ & 0,03 & 0 & 0 & 0 & 0,02 & 0 & 0,01 & 0 & 0,02 & 0,01 & 0 & 0,14 & 0,09 & 0,1 & 0,08 & 0,16 & 0,17 & 0,11 & 0,12 \\
\hline Total & 97,97 & 98,47 & 100 & 98,96 & 99,11 & 99,6 & 99,21 & 97,99 & 100,15 & 96,62 & 99,58 & 97,95 & 95,75 & 97,19 & 96,62 & 97,78 & 97,89 & 98,57 & 98,32 \\
\hline $\mathrm{Si}$ & 11,52 & 11,40 & 11,48 & 11,55 & 11,52 & 11,49 & 11,46 & 11,44 & 11,44 & 11,51 & 11,46 & 6,61 & 6,55 & 6,37 & 6,61 & 6,40 & 6,50 & 6,25 & 6,23 \\
\hline $\mathrm{Al}$ & 4,60 & 4,72 & 4,65 & 4,56 & 4,61 & 4,65 & 4,64 & 4,66 & 4,66 & 4,64 & 4,65 & 1,85 & 1,91 & 2,17 & 2,03 & 1,93 & 1,86 & 2,24 & 2,11 \\
\hline $\mathrm{Ti}$ & 0,00 & 0,00 & 0,00 & 0,00 & 0,00 & 0,00 & 0,00 & 0,01 & 0,00 & 0,01 & 0,00 & 0,16 & 0,15 & 0,07 & 0,07 & 0,21 & 0,27 & 0,05 & 0,07 \\
\hline $\mathrm{Fe}^{2+}$ & 0,02 & 0,01 & 0,01 & 0,02 & 0,00 & 0,01 & 0,01 & 0,01 & 0,01 & 0,02 & 0,02 & 3,36 & 3,51 & 3,20 & 3,40 & 2,88 & 3,27 & 3,11 & 3,02 \\
\hline $\mathrm{Fe}^{3+}$ & & & & & & & & & & & & 0,16 & 0,00 & 0,37 & 0,12 & 0,69 & 0,16 & 0,60 & 0,83 \\
\hline $\mathrm{Mn}$ & 0,00 & 0,00 & 0,01 & 0,00 & 0,00 & 0,00 & 0,00 & 0,00 & 0,00 & 0,00 & 0,00 & 0,09 & 0,09 & 0,08 & 0,07 & 0,09 & 0,07 & 0,09 & 0,08 \\
\hline $\mathrm{Mg}$ & 0,00 & 0,00 & 0,00 & 0,01 & 0,00 & 0,00 & 0,00 & 0,00 & 0,00 & 0,00 & 0,01 & 0,77 & 0,79 & 0,74 & 0,70 & 0,78 & 0,86 & 0,66 & 0,66 \\
\hline $\mathrm{Ca}$ & 0,52 & 0,65 & 0,61 & 0,54 & 0,56 & 0,63 & 0,68 & 0,66 & 0,64 & 0,57 & 0,63 & 1,91 & 2,39 & 1,93 & 1,95 & 1,74 & 1,86 & 1,90 & 1,89 \\
\hline K & 0,02 & 0,04 & 0,06 & 0,03 & 0,02 & 0,03 & 0,04 & 0,03 & 0,03 & 0,05 & 0,03 & 0,32 & 0,29 & 0,36 & 0,24 & 0,29 & 0,40 & 0,38 & 0,33 \\
\hline $\mathrm{Na}$ & 3,01 & 2,87 & 2,82 & 2,99 & 2,95 & 2,79 & 2,77 & 2,84 & 2,91 & 2,80 & 2,83 & 0,30 & 0,34 & 0,36 & 0,35 & 0,37 & 0,33 & 0,38 & 0,35 \\
\hline $\mathrm{Ab}$ & 0,85 & 0,81 & 0,81 & 0,84 & 0,84 & 0,81 & 0,79 & 0,80 & 0,81 & 0,82 & 0,81 & & & & & & & & \\
\hline Or & 0,01 & 0,01 & 0,02 & 0,01 & 0,01 & 0,01 & 0,01 & 0,01 & 0,01 & 0,02 & 0,01 & & & & & & & & \\
\hline Anortita & 0,15 & 0,18 & 0,17 & 0,15 & 0,16 & 0,18 & 0,20 & 0,19 & 0,18 & 0,17 & 0,18 & & & & & & & & \\
\hline $\mathrm{Al}^{\mathrm{IV}}$ & & & & & & & & & & & & 1,39 & 1,54 & 1,63 & 1,39 & 1,60 & 1,50 & 1,75 & 1,77 \\
\hline $\mathrm{Al}^{\mathrm{vI}}$ & & & & & & & & & & & & 0,46 & 0,34 & 0,54 & 0,64 & 0,33 & 0,35 & 0,49 & 0,34 \\
\hline P (kbars) & Johr & son e $\mathrm{R}$ & herfor & & & & & & & & & 4,4 & 4,5 & 5,7 & 5,1 & 4,7 & 4,4 & 6,0 & 5,5 \\
\hline
\end{tabular}


A temperatura que expressa as condições da formação do magma foi estimada com base nos conteúdos de $\mathrm{Zr}$ e SiO$_{2}$ em rochas graníticas de acordo com proposição de Watson e Harrison (1983), já a temperatura de solidificação ou cristalização do granitoide a partir desse magma é sugerida pelo geotermômetro hornblenda-plagioclásio de Blundy e Holland (1990) e Holland e Blundy (1994). No primeiro caso, a correlaçáo negativa entre o elemento $\mathrm{Zr}$ e o conteúdo de $\mathrm{SiO}_{2}$ em rochas graníticas reflete a saturação precoce do Zr no magma e, conforme demonstrado por Watson e Harrison (1983), permite estimar a temperatura do liquidus evidenciando as condiçóes de formação do magma. Segundo essa abordagem, foram obtidas temperaturas liquidus por meio da fórmula $\mathrm{T}^{\circ} \mathrm{C}=-273+[12.900 / 17,8-$ $\ln (\mathrm{Zr})]$, obtendo-se de 893 a $847^{\circ} \mathrm{C}$ para os monzogranitos e de 905 a $896^{\circ} \mathrm{C}$ para os dioritos. $\mathrm{O}$ parâmetro $\mathrm{M}=[\mathrm{K}+\mathrm{Na}+$ $2 \mathrm{Ca}] /\left[\mathrm{Si}{ }^{*} \mathrm{Al}\right]$ foi de 1,62 a 1,48 para os monzo/sienogranitos.

Para utilização do geotermômetro hornblenda-plagioclásio de Blundy e Holland (1990) e Holland e Blundy (1994), foram utilizados dados de Química Mineral do sienogranito. A aplicação desse geotermômetro tem como base a variação do teor de $\mathrm{Al}$ na estrutura de hornblenda e plagioclásio em função da temperatura. Os cálculos de temperatura foram realizados levando em consideração as pressóes calculadas a partir da hornblenda pelo geobarômetro de Johnson e Rutherford (1989) e calibrados para uma reação com quartzo livre: edenita +4 quartzo = tremolita + albita (Blundy e Holland 1990; Holland e Blundy 1994). Aplicando as equaçóes dos respectivos trabalhos para cada par mineral [hornblenda/plagioclásio], obtiveram-se os valores de 785 a $712{ }^{\circ} \mathrm{C}( \pm 75)$ [pares $\mathrm{C} 1-4 /$ C1-7; C2-2/C2-3] e 694 a $581^{\circ} \mathrm{C}$ ( \pm 75$)$ [pares C4-2/C4-2; C2-2/C2-3]. Para a pressão média calculada, as temperaturas médias estimadas são, respectivamente, de 720 e $668^{\circ} \mathrm{C}$.

\section{Geocronologia U-Pb e Geoquímica Isotópica}

Foram coletadas, para este fim, uma amostra do sienogranito (GL-472 - UTM 798078; 9183495), na porção centro-sul do Pluton, e uma amostra de quartzo-diorito (GL-202A - UTM 796203; 9186433), na extremidade noroeste do corpo. $\mathrm{O}$ sienogranito exibe idade-modelo $\mathrm{T}_{\mathrm{DM}}$ $=2,35 \mathrm{Ga}$ e $\varepsilon_{\mathrm{Nd}(580 \mathrm{Ma})}=-18,32$, e o quartzo-diorito forneceu idade-modelo $\mathrm{T}_{\mathrm{DM}}=2,18 \mathrm{Ga}$ e parâmetro $\varepsilon_{\mathrm{Nd}(580 \mathrm{Ma})}=$ $-17,03$. Os dados encontram-se na Tabela 3.
A

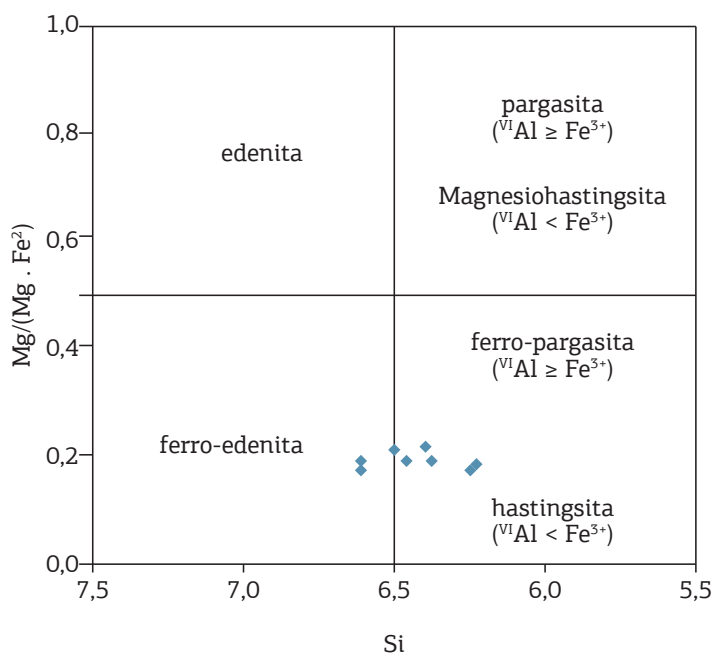

B

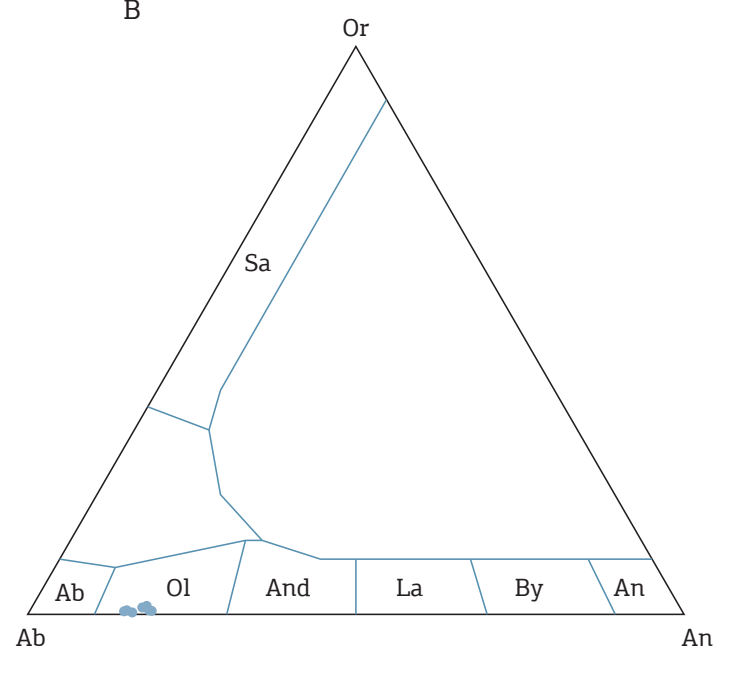

Sa: sanidina; Ab: albita; Ol: oligoclásio; And: andesina; La: labradorita; By: bytownita; An: anortita.

Figura 9. (A) Composições dos anfibólios para amostra da fácies sienogranítica porfíritica baseada no conteúdo de $\mathrm{Si}$ e pela razão $\mathrm{Mg} /\left(\mathrm{Fe}^{+2}+\mathrm{Mg}\right.$ ) para uma relação $\mathrm{Ca}>1,50$; $(\mathrm{Na}+\mathrm{K})>0,50$ e $\mathrm{Ti}<0,50$ (Leake et al. 1997). (B) Composição dos feldspatos da amostra GL-472 - sienogranito do Pluton Bravo.

Tabela 3. Dados analíticos isotópicos Sm/Nd para amostra de quartzo-diorito e sienogranito do Pluton Bravo.

\begin{tabular}{|c|c|c|c|c|c|c|c|}
\hline \multirow{2}{*}{ Litologia } & \multirow{2}{*}{ Sm (ppm) } & \multirow{2}{*}{ Nd (ppm) } & \multirow{2}{*}{${ }^{147} \mathrm{Sm} /{ }^{144} \mathrm{Nd}$} & ${ }^{143} \mathrm{Nd} /{ }^{144} \mathrm{Nd}$ & \multirow{2}{*}{$\varepsilon_{\mathrm{Nd}(0)}$} & \multirow{2}{*}{$\varepsilon_{\mathrm{Nd}(580)}$} & \multirow{2}{*}{$\begin{array}{r}T_{D M} \\
(\mathrm{Ga})\end{array}$} \\
\hline & & & & $( \pm 2 \mathrm{SE})$ & & & \\
\hline GL-202A-Quartzo-diorito & 27,391 & 166,753 & 0,0993 & $0,511396 \pm 11$ & $-24,22$ & $-17,03$ & 2,18 \\
\hline GL-472-Sienogranito & 17,045 & 98,493 & 0,1046 & $0,511350 \pm 17$ & $-25,12$ & $-18,32$ & 2,35 \\
\hline
\end{tabular}


Vinte e nove análises foram efetuadas em zircôes da amostra do sienogranito (GL-472) (Tab. 4). Os grãos de zircão possuem hábito prismático e são euédricos a subédricos, mostrando formas com pronunciadas zonaçóes oscilatórias
(Fig. 10A). Separou-se uma segunda fração de zircôes de cor amarela portando muitas inclusóes.

Uma idade-concórdia de $581 \pm 2 \mathrm{Ma}(\mathrm{n}=4$; MSWD = 0,51 ) foi obtida para o sienogranito, interpretada como a

Tabela 4. Resultados LA-ICPMS U-Th-Pb para zircões do Pluton Bravo, parte central da Província Borborema.

\begin{tabular}{|c|c|c|c|c|c|c|c|c|c|c|c|c|c|c|c|c|}
\hline \multirow{3}{*}{$\begin{array}{l}\text { Amostra } \\
\text { Spots }\end{array}$} & \multirow{3}{*}{ Th/U } & \multicolumn{7}{|c|}{ Razões } & \multirow{3}{*}{$\rho$} & \multicolumn{6}{|c|}{ Idades aparentes } & \multirow{3}{*}{$\begin{array}{c}\text { Conc. } \\
(\%)\end{array}$} \\
\hline & & $206 \mathrm{~Pb}$ & $207 \mathrm{~Pb}$ & \multirow{2}{*}{$+1 \sigma$} & $207 \mathrm{~Pb}$ & \multirow{2}{*}{$+1 \sigma$} & $206 \mathrm{~Pb}$ & \multirow{2}{*}{$+1 \sigma$} & & $207 \mathrm{~Pb}$ & \multirow{2}{*}{ (Ma) } & $207 \mathrm{~Pb}$ & \multirow{2}{*}{ (Ma) } & $206 \mathrm{~Pb}$ & \multirow{2}{*}{ (Ma) } & \\
\hline & & $204 \mathrm{~Pb}$ & $206 \mathrm{~Pb}$ & & $235 U$ & & $238 U$ & & & $206 \mathrm{~Pb}$ & & $235 \mathrm{U}$ & & $238 U$ & & \\
\hline \multicolumn{17}{|l|}{ GL-472 } \\
\hline $\mathrm{Z11}$ & 0,57 & 81534 & 0,05959 & 1,17 & 0,7399 & 1,30 & 0,09006 & 0,57 & 0,59 & 589 & 25 & 562 & 6 & 556 & 3,04 & 94 \\
\hline $\mathrm{Z} 20$ & 0,22 & 179063 & 0,05834 & 0,48 & 0,7599 & 0,75 & 0,09447 & 0,59 & 0,72 & 542 & 10 & 574 & 3 & 582 & 3,26 & 107 \\
\hline Z9 & 0,30 & 10255 & 0,05946 & 0,45 & 0,7635 & 0,70 & 0,09312 & 0,54 & 0,70 & 584 & 10 & 576 & 3 & 574 & 2,94 & 98 \\
\hline Z29 & 0,34 & 1749 & 0,05892 & 0,88 & 0,7702 & 1,15 & 0,09481 & 0,74 & 0,61 & 564 & 19 & 580 & 5 & 584 & 4,15 & 104 \\
\hline Z19 & 0,44 & 44218 & 0,05960 & 0,63 & 0,7745 & 1,04 & 0,09425 & 0,82 & 0,77 & 589 & 14 & 582 & 5 & 581 & 4,58 & 99 \\
\hline Z15 & 0,26 & 262749 & 0,05971 & 0,80 & 0,7755 & 1,03 & 0,09420 & 0,65 & 0,76 & 593 & 17 & 583 & 5 & 580 & 3,60 & 98 \\
\hline $\mathrm{Z} 26$ & 0,24 & 56428 & 0,05970 & 0,92 & 0,7766 & 1,17 & 0,09435 & 0,72 & 0,74 & 593 & 20 & 584 & 5 & 581 & 3,99 & 98 \\
\hline $\mathrm{Z} 23$ & 0,95 & 38814 & 0,06128 & 0,94 & 0,7728 & 1,24 & 0,09146 & 0,81 & 0,62 & 649 & 20 & 581 & 5 & 564 & 4,37 & 87 \\
\hline $\mathrm{Z} 18$ & 1,11 & 266 & 0,05662 & 1,71 & 0,6931 & 2,56 & 0,08877 & 1,78 & 0,88 & 477 & 37 & 535 & 11 & 548 & 10,02 & 115 \\
\hline $\mathrm{Z} 12$ & 0,74 & 6155 & 0,06399 & 1,00 & 0,7891 & 1,23 & 0,08943 & 0,72 & 0,54 & 741 & 21 & 591 & 6 & 552 & 3,79 & 74 \\
\hline $\mathrm{Z} 25$ & 1,14 & 8350 & 0,06274 & 0,88 & 0,7698 & 1,16 & 0,08898 & 0,75 & 0,61 & 700 & 19 & 580 & 5 & 549 & 3,94 & 79 \\
\hline $\mathrm{Z} 22$ & 1,25 & 5260 & 0,06390 & 14,13 & 0,7986 & 14,18 & 0,09063 & 1,20 & 0,16 & 738 & 299 & 596 & 64 & 559 & 6,45 & 76 \\
\hline $\mathrm{Z} 27$ & 1,07 & 6194 & 0,06406 & 2,16 & 0,8043 & 3,04 & 0,09105 & 2,14 & 0,70 & 744 & 46 & 599 & 14 & 562 & 11,52 & 76 \\
\hline $\mathrm{Z5}$ & 1,08 & 3060 & 0,06311 & 0,78 & 0,8203 & 1,20 & 0,09427 & 0,92 & 0,74 & 712 & 17 & 608 & 6 & 581 & 5,08 & 82 \\
\hline Z8 & 0,82 & 9414 & 0,06460 & 1,92 & 0,8209 & 2,03 & 0,09217 & 0,68 & 0,30 & 761 & 40 & 609 & 9 & 568 & 3,68 & 75 \\
\hline $\mathrm{Z} 24$ & 0,63 & 1000 & 0,07685 & 5,01 & 0,8731 & 7,63 & 0,08240 & 5,75 & 0,75 & 1117 & 100 & 637 & 36 & 510 & 28,22 & 46 \\
\hline $\mathrm{Z1}$ & 0,98 & 6875 & 0,07355 & 1,03 & 0,8830 & 1,48 & 0,08707 & 1,07 & 0,70 & 1029 & 21 & 643 & 7 & 538 & 5,51 & 52 \\
\hline $\mathrm{Z4}$ & 0,64 & 3818 & 0,07210 & 1,29 & 0,9113 & 1,40 & 0,09167 & 0,56 & 0,34 & 989 & 26 & 658 & 7 & 565 & 3,01 & 57 \\
\hline $\mathrm{Z3}$ & 0,99 & 5410 & 0,07959 & 2,63 & 0,9671 & 2,99 & 0,08813 & 1,42 & 0,71 & 1187 & 52 & 687 & 15 & 544 & 7,43 & 46 \\
\hline $\mathrm{Z} 28$ & 0,65 & 1295 & 0,07648 & 1,06 & 0,9886 & 2,04 & 0,09376 & 1,74 & 0,85 & 1108 & 21 & 698 & 10 & 578 & 9,64 & 52 \\
\hline $\mathrm{Z13}$ & 1,14 & 1151 & 0,08087 & 0,76 & 1,0154 & 1,10 & 0,09106 & 0,79 & 0,69 & 1218 & 15 & 712 & 6 & 562 & 4,25 & 46 \\
\hline $\mathrm{Z14}$ & 0,99 & 5459 & 0,08907 & 1,83 & 1,1375 & 2,26 & 0,09262 & 1,33 & 0,58 & 1406 & 35 & 771 & 12 & 571 & 7,27 & 41 \\
\hline Z6 & 1,01 & 773 & 0,08640 & 2,39 & 1,1464 & 2,68 & 0,09624 & 1,21 & 0,44 & 1347 & 46 & 776 & 15 & 592 & 6,87 & 44 \\
\hline $\mathrm{Z10}$ & 0,37 & 343 & 0,09675 & 2,62 & 1,1683 & 2,83 & 0,08758 & 1,07 & 0,36 & 1562 & 49 & 786 & 16 & 541 & 5,56 & 35 \\
\hline Z16 & 1,09 & 819 & 0,09155 & 4,66 & 1,2325 & 4,84 & 0,09764 & 1,33 & 0,27 & 1458 & 89 & 815 & 27 & 601 & 7,63 & 41 \\
\hline $\mathrm{Z} 21$ & 1,11 & 534 & 0,10176 & 2,30 & 1,3105 & 2,93 & 0,09341 & 1,82 & 0,62 & 1656 & 43 & 850 & 17 & 576 & 10,04 & 35 \\
\hline \multicolumn{17}{|l|}{ Herança } \\
\hline $\mathrm{Z7}$ & 0,90 & 206 & 0,21496 & 7,98 & 2,6867 & 9,03 & 0,09065 & 4,22 & 0,72 & 2943 & 129 & 1325 & 67 & 559 & 22,63 & 19 \\
\hline $\mathrm{Z} 2$ & 0,46 & 71266 & 0,12593 & 0,58 & 5,2251 & 0,82 & 0,30094 & 0,58 & 0,65 & 2042 & 10 & 1857 & 7 & 1696 & 8,66 & 83 \\
\hline $\mathrm{Z17}$ & 0,47 & 40918 & 0,13969 & 0,61 & 8,4887 & 0,88 & 0,44072 & 0,63 & 0,66 & 2223 & 11 & 2285 & 8 & 2354 & 12,36 & 106 \\
\hline
\end{tabular}


idade de cristalização do Pluton Bravo (Fig. 10B). Essa idade é similar, considerando o erro, à idade média ponderada $\mathrm{Pb}^{207} / \mathrm{Pb}^{206}$ de $585 \pm 6 \mathrm{Ma}(\mathrm{n}=5$; MSWD = 1,5). Três zircôes da fração amarela apresentaram muita variação no sinal analítico, devido às inclusões, e foram considerados como herança de idade paleoproterozoica, cujo único zircão obtido com concordância aceitável sem perda de chumbo perfaz uma idade em torno de 2,2 Ga (Tab. 4).

\section{DISCUSSÕES}

O Pluton Bravo foi formado durante o Ciclo Orogenético Brasiliano, dada a sua idade de cristalização próxima de $581 \mathrm{Ma}$. O acervo de estruturas magmáticas e deformacionais indica que a colocação do corpo ocorreu em regime transtrativo, associado a zonas de cisalhamento conjugadas. As características geoquímicas dos litotipos estudados remetem à similaridade dessas rochas com granitos tipo-A, conforme discriminado em Whalen et al. (1987) (Fig. 11).

As hornblendas analisadas expressam baixas razōes $\mathrm{Fe}^{3+}$ $\left(\mathrm{Fe}^{3+}+\mathrm{Fe}^{2+}\right)<<0,20$ e possuem alto \#Fe $(>0,81)$, contrastando com anfibólios de granitos cálcio-alcalinos normais e outros granitos cristalizados em ambiente com alta e média $\mathrm{fO}_{2}$, cujos experimentos idealizam valores entre $\mathrm{Fe}^{3+} /\left(\mathrm{Fe}^{3+}+\right.$ $\left.\mathrm{Fe}^{2+}\right)>0,20$ e \#Fe $(0,40-0,65)$. (Schmidt 1992; Anderson e Smith 1995). As razóes acima apresentadas pelas análises do Pluton Bravo sugerem a ocupação do sítio estrutural M2 das hornblendas por ${ }^{\mathrm{VI}} \mathrm{Al}$ em detrimento de $\mathrm{Mg}$ e Fe$^{3+}$, o que é compatível com cristalização em ambiente com baixa $\mathrm{fO}_{2}$ (Anderson e Smith 1995). Tais substituições, passíveis de ocorrer em granitos anorogênicos e outros cristalizados em ambiente de baixa $\mathrm{fO}_{2}$, formam anfibólios ferrosos anomalamente enriquecidos em $\mathrm{Al}$. O Al excedente, por sua vez, tende a superestimar os valores de pressão para os geobarômetros clássicos. Portanto, as pressóes estimadas entre 4,4 e 6 kbar sugerem as pressóes máximas possíveis para o alojamento do corpo, sendo preferencial adotar o limite inferior obtido, que, com as feiçóes de stopping magmático, remete à interface da crosta superior com a crosta média.

O fracionamento de K-feldspatos é outra importante característica atribuída à gênese de granitos tipo-A. No caso desse corpo, a correlaçáo positiva entre as razões $\mathrm{Rb} / \mathrm{Sr}$ e $\mathrm{Rb} /$ Ba é sugestiva de fracionamento de K-feldspatos (Fig. 12A), enquanto o aumento da razão $\mathrm{Ga} / \mathrm{Al}$ associado à diminuição da razão $\left(\mathrm{Eu} / \mathrm{Eu}^{*}\right)_{\mathrm{N}}$ sugere fracionamento de plagioclásio a partir da estabilidade de Ga em magmas ricos em flúor (Fig. 12B). As anomalias negativas de Sr e Eu nos spidergrams também são um indicativo de que o fracionamento de plagioclásio foi um processo importante durante a cristalizaçáo do corpo.

$\mathrm{O}$ fornecimento de $\mathrm{F}^{-2}$ dado pela fusão por desidratação de biotita é outra característica evocada para a evolução de magma granítico tipo-A (Frost e Frost 2011). Nesse caso, o baixo conteúdo de água estrutural $(\mathrm{PF}<0,8)$, aliado às altas temperaturas estimadas para o liquidus $\left(>847^{\circ} \mathrm{C}\right)$ do magma, é compatível com tal mecanismo.

Desde a concepção dos granitos tipo-A, definida por Loiselle e Wones (1979), e posterior expansão para um amplo grupo de granitoides com características similares e origens diversas, sintetizados em Collins et al. (1982) e Whalen et al. (1987), há uma constante controvérsia em
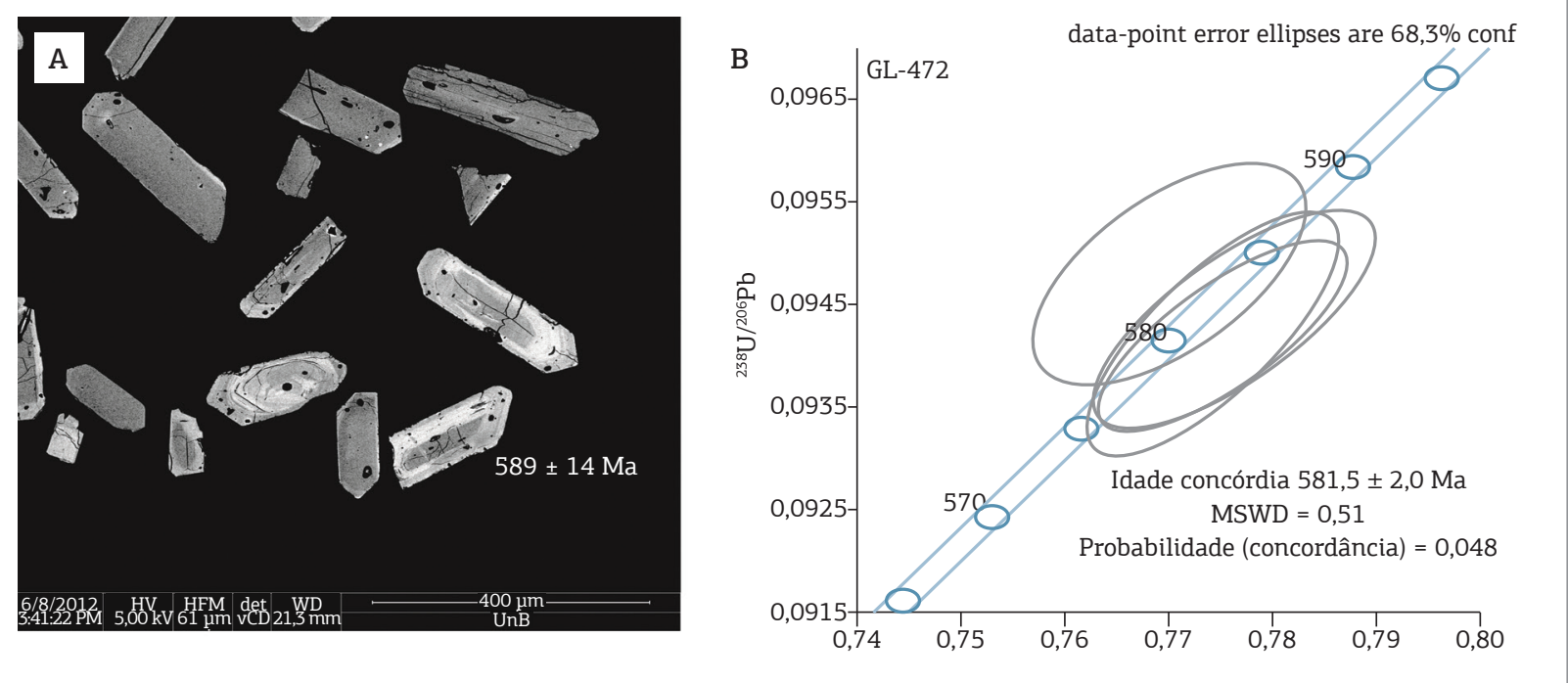

Figura 10. (A) Imagem por retroespalhamento de elétrons obtidas a partir de MEV para população de zircões euédricos com pronunciada zonação oscilatória. (B) Diagrama Concórdia com idade aparente obtida de $581 \pm 2 \mathrm{Ma}$ ( $n=4 ;$ MSWD = 0,51) para uma amostra sienogranítica do Pluton Bravo. 

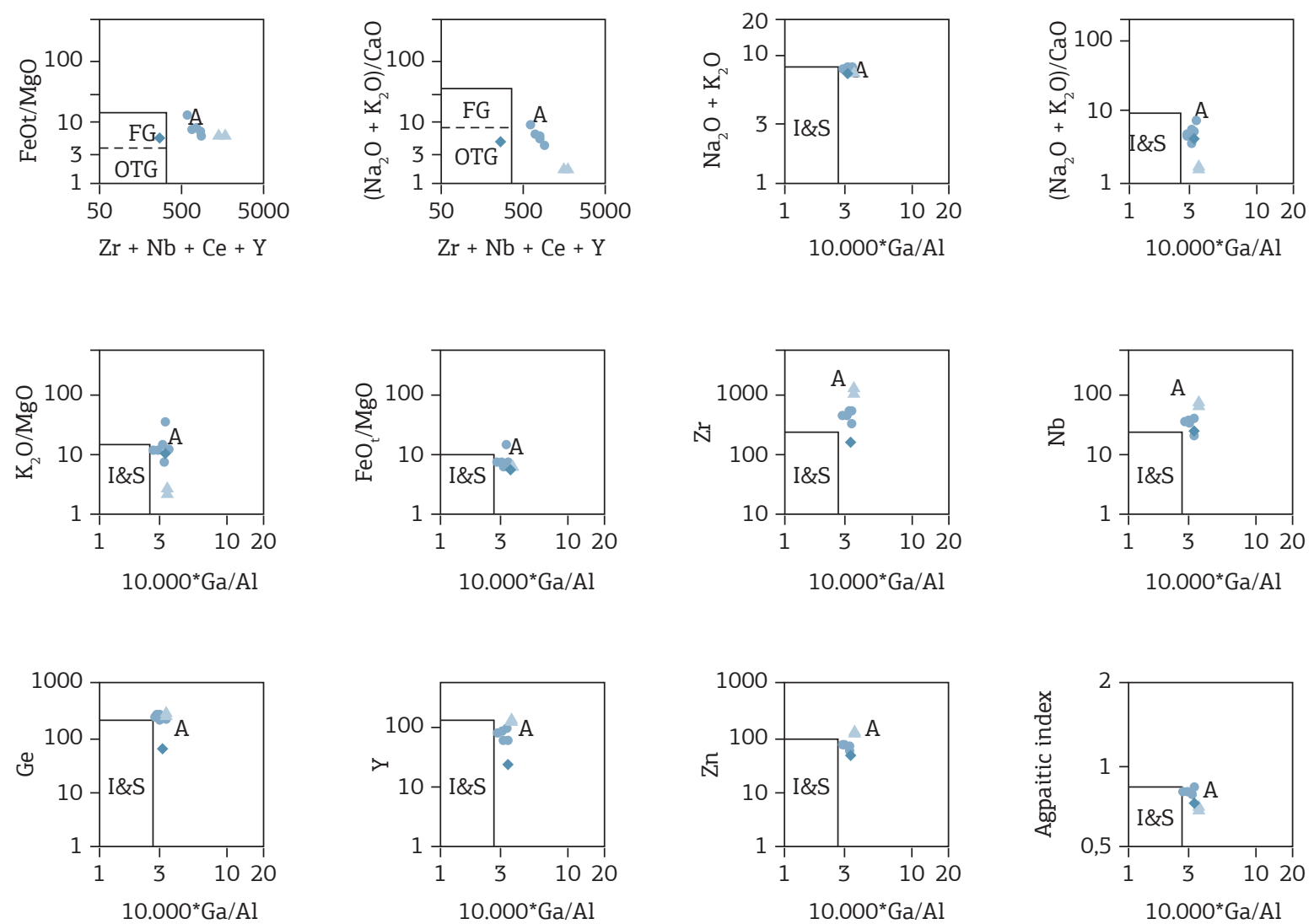

FG: campo de granito fracionado; OTG: campo de granito não fracionado. Os símbolos são os mesmos da Figura 6.

Figura 11. Diagramas de elementos traços e razões discriminantes de ambiente tectônico de Whalen et al. (1987) evidenciando o comportamento químico similar das amostras do Pluton Bravo com granitos tipo-A. I-, S- e A: granitoides tipo I, S e A.

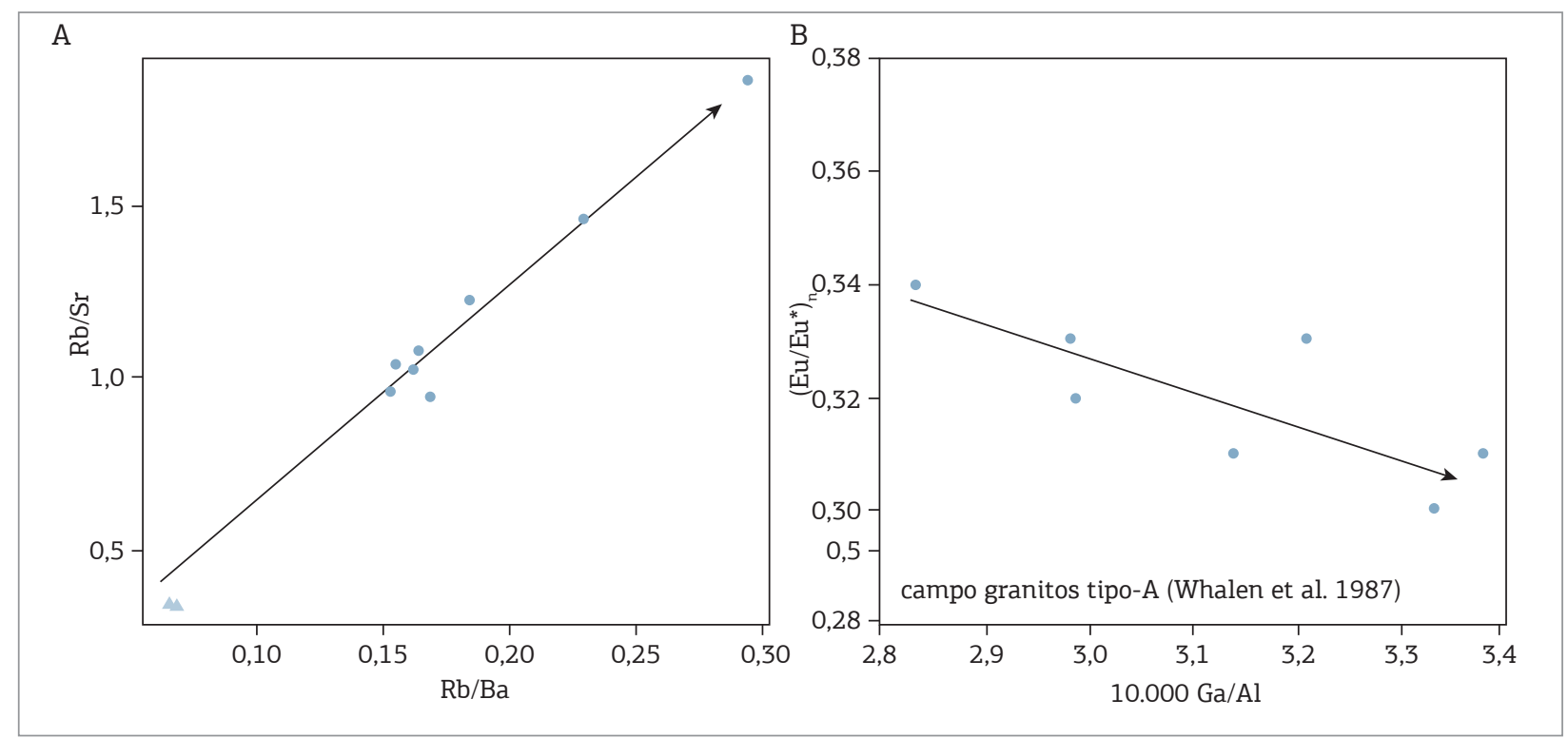

Figura 12. Diagramas de $\mathrm{Rb} / \mathrm{Ba} \times \mathrm{Rb} / \mathrm{Sr}(\mathrm{A})$ e $\left(\mathrm{Eu} / \mathrm{Eu}^{*}\right)_{\mathrm{N}} \times 10.000 \mathrm{Ga} / \mathrm{Al}$ (B) que apontam para a importância do fracionamento de feldspatos na evolução dos granitos do Pluton Bravo. 
torno da utilização do termo "tipo-A" como sinônimo de "anorogênico, aluminoso, anidro, alcalino, ambíguo, etc". De acordo com a classificação proposta por Frost et al. (2001) e Middlemost (1997), os sienogranitos porfiríticos do Pluton Bravo podem ser classificados como granitos transalcalinos ferrosos, álcali-cálcicos metaluminosos a levemente peraluminosos. Os dioritos diferenciam-se por apresentarem assinaturas geoquímicas similares às de basaltos alcalinos, consoante a outras intrusóes do gênero descritas na Província Borborema (Guimarães et al. 2011). No caso do Pluton Bravo, a relaçáo com as zonas de cisalhamento transcorrentes, a assinatura pós-colisional de acordo com o diagrama de Pearce et al. (1996) e a idade de cristalização permitem-nos correlacioná-lo com litotipos que apresentam característica de granitos tipo-A sem, contudo, associá-los diretamente a rochas derivadas em ambiente anorogênico.

Uma possibilidade de geração de granitos com características do tipo-A evoca o modelo clássico de uma fonte residual granulítica (Collins et al. 1982; Clemens et al. 1986; Whalen et al. 1987). Nesse modelo, o Pluton Bravo se formaria a partir de um restito félsico granulítico, resultante da extração prévia de granitoides tipo-I de alto $\mathrm{K}$ e com assinaturas similares a ambientes de subducção (período entre 590 e $580 \mathrm{Ma}$ ), tal qual apresentado para outros exemplos do Domínio Central da Província Borborema (Almeida et al. 2002; Guimarães et al. 2004; Guimarães et al. 1998; 1999). Contudo, a idade obtida de $581 \mathrm{Ma}$ limita essa possibilidade. $\mathrm{O}$ alto teor de $\mathrm{K}_{2} \mathrm{O}$ das rochas estudadas também desfavorece a fusão de um resíduo que tenha gerado previamente granitoides do tipo-I enriquecidos em $\mathrm{K}$.

As idades-modelo maiores que 2,1 Ga, que são mais comuns nos granitoides de 570 a $575 \mathrm{Ma}$ (Guimarães et al. 2004; Van Schmus et al. 2011), indicam a importância de fontes crustais paleoproterozoicas na formação desses magmas ou metassomatismo relacionado à subducção do manto litosférico subcontinental de idade paleoproterozoica. No caso da participação de fontes crustais, os dados de $\mathrm{Sm}-\mathrm{Nd}$, em conjunto com a idade de cristalização obtida, favorecem a hipótese de fusão parcial direta de rochas paleoproterozoicas metamorfizadas na fácies granulito. Regionalmente, tais litologias, que incluem componentes graníticas a granodioríticas e, em menor parte, tonalíticas, estão presentes no Complexo Cabaceiras, encaixante do pluton, que possui características anidras, portando, em parte, paragêneses de fácies granulito. Dentre essas paragêneses minerais pode-se citar forsterita-hercinita-diopsídio metacarbonatos (Carmona 2006; Marinho et al. 2008; Ventura Santos et al. 2013; Santos et al. 2013; Lages 2012) e granada granulito charnoquítico mesopertítico (Neves et al. 2015; Lages 2012).

A associação com rochas máficas apresentando similaridades geoquímicas e isotópicas com os sienogranitos, tais como comportamento dos ETRs, baixo $\varepsilon_{\mathrm{Nd}}$ e idademodelos próximas, e a presença de zircóes herdados podem indicar que houve algum processo de diferenciação entre o magma máfico (underplated?) enriquecido em álcalis, $\mathrm{Zr}$, $\mathrm{Nb}, \mathrm{Y}$ e $\Sigma$ ETR e a fusão de crosta inferior paleoproterozoica. Um manto litosférico metassomatizado durante processos de subducção paleoproterozoica é proposto como área-fonte de magmas que deram origem a enclaves máficos na parte central da Província Borborema (Neves e Mariano 1997; Guimarães e Da Silva Filho 1998; Mariano et al. 2001).

Segundo Frost e Frost (2011), a associação de magmas máficos e as elevadas temperaturas observadas para granitoides ferrosos $\left(>900^{\circ} \mathrm{C}\right)$ sugerem a atuação em conjunto dos mecanismos de diferenciação de magmas basálticos alcalinos e a assimilação de crosta félsica.

No caso do Pluton Bravo, as temperaturas liquidus baseadas na saturação de zircão de 893 a $847^{\circ} \mathrm{C}$ para os monzogranitos e de 905 a $896^{\circ} \mathrm{C}$ para os dioritos são próximas das temperaturas necessárias para a geração de magmas ferrosos (a partir da fusão parcial de crosta tonalítica a granodiorítica) capazes de gerar granitos tipo-A em ausência de fases vaporizadas. A coexistência de magmas máficos e as pressóes estimadas de colocação da ordem de 13 e $<21 \mathrm{~km}$ de profundidade (levando em consideração o patamar inferior) são aspectos sugestivos de um modelo de afinamento da litosfera subcontinental enriquecida por remoção convectiva com ascensão da astenosfera quente, que elevou a temperatura o suficiente para fundir-se em um melt rico em elementos incompatíveis. Modelo sugerido é proposto para os granitos pós-colisionais do Orógeno Svecofennian (Väisänen et al. 2000).

Para Frost e Frost (2011), o decréscimo de pressão é um fator controlador de assimilação/fusão da crosta félsica, onde o caráter metaluminoso a levemente peraluminoso de algumas amostras pode ocorrer em função da mistura incompleta dessas fontes (máficas e félsicas) ou assimilação de diferentes quantidades de crosta félsica. Patiño Douce (1997) demonstrou ser possível a geração de granitos com assinatura do tipo-A metaluminosos pela fusão de granitoides cálcio-alcalinos (granodiorítico e tonalítico) a baixa pressão de formação ( $\mathrm{P} \leq 4 \mathrm{Kbar}$ e parcialmente por $\mathrm{P}<8 \mathrm{Kbar}$ ) e pelo baixo conteúdo de $\mathrm{H}_{2} \mathrm{O}$ da fonte.

Frost e Frost (2011) advogam, a partir da petrologia experimental, que a fusão de rochas tonalíticas irá produzir granitoides ferrosos com elevado conteúdo de sílica e assinatura cálcio-alcalina, sendo necessário elevado grau de fusão parcial para gerar magmas de composição álcali-cálcica. Já a produção de magmas de caráter metaluminoso a levemente peraluminosos está restrita a baixas pressóes, ao passo que elevadas pressōes dão origem a magmas fortemente peraluminosos. Sendo assim, a gênese do Pluton Bravo exigiu 
elevado grau de fusão parcial de rochas quartzo-feldspáticas (não tonalíticas?) para formar granitoides ferrosos com algumas amostras com conteúdo de sílica $<70 \%$ e composição álcali-cálcica, e o caráter metaluminoso a levemente peraluminoso é compatível com a pressão estimada $>4 \mathrm{e}<8 \mathrm{kbar}$.

As fortes características químicas similares às de granito tipo-A aluminosos, de King et al. (1997), do Pluton Bravo e as idades-modelo maiores que 2,1 Ga sáo mais parecidas com os granitos de ca. $570 \mathrm{Ma}$ da Zona Transversal (estágio IV de Van Schmus et al. 2011; grupo 3 de Guimarães et al. 2004); entretanto, a idade obtida de $581 \mathrm{Ma}$ equivale à faixa dos granitos transicionais do regime compressivo para o transcorrente registrado na Zona Transversal (estágio III de Van Schmus et al. 2011; grupo 2 de Guimarães et al. 2004).

O Pluton Bravo é notadamente comparável ao granitoide transalcalino de Solânea no Domínio Rio Grande do Norte (Guimarães et al. 2009), que também é similar aos granitos transalcalinos ferro-potássicos do leste da Nigéria (Ferré et al. 1998). Essa correspondência também se estende ao comportamento químico das fácies dioríticas, tais como $\mathrm{Zr}$ >> (400 ppm), $\mathrm{TiO}_{2}-1,8 \%$ e $\mathrm{Nb}>(30 \mathrm{ppm})$ e presença de ferro-hornblendas. $\mathrm{O}$ magmatismo transalcalino encontrado na Borborema e em parte da Nigéria pode ser atribuído a um evento extensivo (Guimaráes et al. 2009) na consolidação do Supercontinente Gondwana entre 580 e $570 \mathrm{Ma}$.

\section{CONCLUSÕES}

O caráter conjugado e a cinemática sinistral e dextral das zonas de cisalhamento transcorrentes, respectivamente de direção NE-SW e E-W, devem ter fornecido paleotensōes extensionais propícias para a colocação do Pluton Bravo. Esse fato é reforçado pelas feiçôes que indicam que o magmatismo foi contemporâneo à deformaçấo, conforme expresso no paralelismo entre a trama magmática e a trama deformacional. Dessa forma, a idade de $581 \pm 2$ Ma marca a idade mínima de ativação dessas zonas de cisalhamento.

As rochas porfíriticas do Pluton Bravo são geoquimicamente similares a granitos do tipo-A e sua intrusão está associada ao estágio magmático pós-colisional, originado pela combinaçấo de alto grau de fusão parcial de porçáo félsica (granodiorítica, monzodiorítica a tonalítica) da parte inferior de crosta paleoproterozoica com importante participaçáo de magma de origem mantélica anomalamente enriquecido. O magma máfico deu origem a monzonitos e dioritos com alto $\mathrm{Zr}$, Nb e ETR que são geoquimicamente similares e mais enriquecidos que os sienogranitos estudados. Eles também compartilham semelhanças isotópicas, tais como baixo $\varepsilon_{\mathrm{Nd}}$ e idades-modelo $>$ 2,1 Ga.

A relação entre a idade e as características geoquímicas e isotópicas deste pluton destoa de outros granitos similares na Zona Transversal. Nesse sentido, a transiçấo do regime compressional para eminentemente direcional com componente extensional se deu um pouco antes $(-580 \mathrm{Ma})$ para esta porção do Domínio Central da Província Borborema evidenciando o caráter episódico e diacrônico do Evento Orogenético Brasiliano.

Esse granitoide constitui um bom exemplo de magmatismo pós-colisional transalcalino no Domínio Central, que, com outros exemplos no Domínio Rio Grande do Norte e no leste da Nigéria, sugere um afinamento convectivo da litosfera subcontinental entre 580 e 570 Ma na consolidação do Supercontinente Gondwana.

\section{REFERÊNCIAS}

Almeida F.F.M. (1967). Origem e evolução da Plataforma Brasileira. Rio de Janeiro: DNPM-DGM, Boletim, 241, 36 p.

Almeida F.F.M., Hasui Y., Brito Neves B.B., Fuck R. (1977). Províncias estruturais brasileiras. In: VIII Simpósio de Geologia do Nordeste, Campina Grande: SBG. p. 363.

Almeida C.N. de, de Pinho Guimarães I., da Silva Filho A.F. (2002). A-Type Post-Collisional Granites in the Borborema Province - NE Brazil: The Queimadas Pluton. Gondwana Research, 5:667-681. doi:10.1016/S1342-937X(05)70637-7.

Anderson L.A., Smith D.R. (1995). The effects of temperature and $\mathrm{fO}_{2}$ on the Al-in-hormblende barometer. American Mineralogist, 80:549-559.

Best M.G. Igneous and Metamorphic Petrology. (2008). $2^{\text {nd }}$ ed. Malden: Blackwell Science Ltd., 729 p.

Blundy J.D., Holland T.J.B. (1990). Calcic amphibole equilibria and a new amphibole-plagioclase geothermometer. Contributions to Mineralogy and Petrology, 104:208-224.
Bonin B. (2004). Do coeval mafic and felsic magmas in post-collisional to within-plate regimes necessarily imply two contrasting, mantle and crustal, sources? A review. Lithos, 78:1-24.

Boynton W.V. (1984). Geochemistry of the rare earth elements: meteorite studies. In: Henderson P. (Ed.). Rare Earth Element Geochemistry. Amsterdam: Elsevier, p. 63-114.

Brasilino R.G., Miranda A.W.A., Lages G.A., Medeiros V.C. (2009). Caracterização Geoquímica dos Ortognaisses da Suíte CarnoióCaturité, ao Norte da Folha Santa Cruz do Capibaribe (SB-24-Z-DVI) e Sul da Folha Boqueirão (SB-24-Z-D-III), Província Borborema. In: XII Congresso Brasileiro de Geoquímica, 2009, Ouro Preto. Ouro Preto: Ufop, 2009. Resumo.

Brasilino R.G., Miranda A.W.A., Lages G.A., Rodrigues J.B. (2012), Petrography, Geochemistry and Geochronology (U-Pb) of Metamafic Rocks From Cabaceiras Complex, Northeast, Brazil: Geodinamic Implication. In: VIII South-American Symposiun on Isotopic Geology, 2012, Medellin. Boletin de resumos. 
Brasilino R.G., Miranda A.W.A., Marinho S.M. (2012). Programa Geologia do Brasil. Carta Geológica Escala 1:100.000: Folha SB.24Z-D-VI, Santa Cruz do Capibaribe. CPRM Serviço Geológico do Brasil. Disponível em: <http://geobank.cprm.gov.br/pls/publico/geobank. download.downloadlayouts?p_webmap $=$ N\&p_usuario=1>. Acesso em 08 de fev. de 2016

Brito Neves B.B., Santos E.J., Van Schmus W.R. (2000). Tectonic history of the Borborema Province, Northeastern Brazil. In: Cordani, U. G., Milani, E. J., Thomaz Filho, A., Campos, D. A. Tectonic Evolution of South America. Rio de Janeiro: 31 $1^{\text {st }}$ International Geological Congress. p. 151-182.

Buhn B., Pimentel M.M., Matteini M., Dantas E L. (2009). High spatial resolution analysis of $\mathrm{Pb}$ and $\mathrm{U}$ isotopes for geochronology by laser ablation multi-collector inductively coupled plasma mass spectrometry (LA-MC-ICP-MS). Anais da Academia Brasileira de Ciências, 81:1-16.

Carmona L.C.M. (2006). Estudo geológico e geoquímico da região compreendida entre Fagundes e Itatuba (PB), Terreno Alto Moxotó, Nordeste do Brasil. Tese (Doutorado) - Centro de Tecnologia e Geociências, Universidade Federal de Pernambuco, 337 p.

Clemens J.D., Holoway J.R., White A.J.R. (1986) Origin of in the A-type granite: experimental constraints. American Mineralogist, 71:317-324.

Collins W.J., Beams S.D., White A.J.R., Chappel B.W. (1982) Nature and origin of the A-types granites with particular reference to southeastern Australia. Contributions to Mineralogy and Petrology, 80:189-200

Conticelli S., Peccerillo A. (1992). Petrology and geochemistry of potassic and ultrapotassic volcanism from Central Italy: inferences on its genesis and on the mantle source evolution. Lithos, 28:221-240.

Droop G.T.R. (1987). A general equation for estimating Fe3+ concentrations in ferromagnesian silicates and oxides from microprobe analyses, using stoichiometric criteria. Mineralogical Magazine, 51:431-435.

Eby G.N. (1990). The A-type granitoids: A review of their occurrence and chemical characteristics and speculations on their petrogenesis. Lithos, 26:115-134.

Eby G.N. (1992). Chemical subdivision of the A-type granitoids: petrogenic and tectonic implications. Geology, 20:641-644

Ferré E.C., Caby R., Peucat J.J., Capdevila R., Monié P. (1998). PanAfrican, postcollisional, ferro-potassic granite and quart-monzonite plutons of Eastern Nigeria. Lithos, 45:255-279.

Ferreira V.P., Sial A.N., Jardim de Sá E.F. (1998). Geochemical and isotopic signatures of Proterozoic granitoids in terranes of Borborema province, northeastern Brazil. Journal of South America Earth Sciences, 11:439-455.

Ferreira V.P., Sial A.N., Pimentel M.M., Moura C.A.V. (2004). Intermediate to acidic magmatism and crustal evolution in the Transversal Zone, Northeastern Brazil. In: Mantesso Neto V., Bartorelli A., Carneiro C.D.R., Brito Neves B.B. (Eds.) Geologia do Continente Sul-Americano: A evolução da obra de Fernando Flávio de Almeida. São Paulo: Editora Beca, p. 189-201.

Frost B.R., Barnes C., Collins W, Arculus R., Ellis D., Frost C. (2001). A chemical classification for granitic rocks. Journal of Petrology, 42:2033-2048

Frost C.D., Frost B.R. (2011). On Ferroan (A-type) Granitoids: their Compositional Variability and Modes of Origin. Journal of Petrology, 52:39-53.
Gióia S.M.C.L., Pimentel M.M. (2000). The Sm-Nd isotopic method in the geochronology laboratory of the University of Brasília. Anais da Academia Brasileira de Ciências, 72:220-245.

Gualda G.A.R., Vlach S.R.F. (2005). Stoichiometry-based estimates of ferric iron in calcic, sodic-calcic and sodic amphiboles: a comparison of various methods. Anais da Academia Brasileira de Ciências, 77(3):521-534

Guimarães I.P., da Silva Filho A.F. (1998). Nd- and Sr- isotopic and $\mathrm{U}-\mathrm{Pb}$ geochronologic constraints for the evolution of the shoshonitic Brasiliano Bom Jardim and Toritama complexes: evidence for a Transamazonian enriched mantle under Borborema tectonic province, Brazil. International Geology Review, 40:500-527.

Guimarães I.P., da Silva Filho A.F., Almeida C.N., Araújo J.M.M., Sales A., Melo S.C. (1998). The Brasiliano Granitoids from the Pajeú Paraíba Belt and Teixeira High: Sm-Nd Isotope Geochemistry and $\mathrm{U} / \mathrm{Pb}$ in Zircon Ages. In: XL Congresso Brasileiro de Geologia, Belo Horizonte, p. 48

Guimarães I.P., da Silva Filho A.F., Almeida C.N., Melo E.B., Araújo J.M.M., Sales A. (1999). Sm-Nd isotopoe geochemistry and U/Pb zircon ages of the Brasiliano granitoids from the Pajeu-Paraiba Terrain, Borborema Province, northeastern Brazil. In: II South American Symp. Isotope Geology, Córdoba, p. 300-30.

Guimarães I.P., da Silva Filho A.F., Almeida C.N., Van Schmus W.R., Araújo J.M.M., Melo S.C., Melo E.B. (2004). Brasiliano (Pan-African) granitic magmatism in the Pajeú-Paraíba belt, Northeast Brazil: An isotopic and geochronological approach. Precambrian Research, 135:23-53. doi:10.1016/j.precamres.2004.07.004

Guimarães I.P., da Silva Filho A.F., Melo S.C., Macambira M.B. (2005). Petrogenesis of A-type Granitoids from the Alto Moxoto and Alto Pajeu Terranes of the Borborema Province, NE Brazil: Constraints from Geochemistry and Isotopic Composition. Gondwana Research, 8(3):347-362.

Guimarães I.P., da Silva Filho A.F., de Araújo D.B., de Almeida C.N., Dantas E. (2009). Trans-alkaline magmatism in the Serrinha-Pedro Velho Complex, Borborema Province, NE Brazil and its correlations with the magmatism in eastern Nigeria. Gondwana Research, 15:98110. doi:10.1016/j.gr.2008.06.011

Guimarães I.P., da Silva Filho A.F., Almeida C.N., Macambira M.B., Armstrong R. (2011). U-Pb SHRIMP data constraints on calcalkaline granitoids with 1.3-1.6 Ga Nd $\mathrm{T}_{\mathrm{DM}}$ model ages from the central domain of the Borborema province, NE Brazil. Journal of South American Earth Sciences, 31:383-396. doi:10.1016/j. jsames.2011.03.001

Hammarstron J.M., Zen E-An. (1986). Aluminum in hornblende: An empirical igneous geobarometer. American Mineralogist, 71:1297-1313.

Holland T.J.B., Blundy J.D. (1994). Non-ideal interaction in calcic-amphiboles and their bearing on amphibole-plagioclase thermometry. Contributions to Mineralogy and Petrology. 116:433-447.

Irvine T.N., Baragar W.R.A. (1971). A guide to the chemical classification of the common volcanic rocks. Canadian Journal of Earth Sciences, 8:523-548.

Jardim de Sá E.F. (1994). A Faixa Seridó (Província da Borborema, NE do Brasil) e o seu significado geodinâmico na cadeia Brasiliana/PanAfricana. Tese (Doutorado) - Universidade de Brasília.

Johnson M.C., Rutherford M.J. (1989). Experimental calibration of the aluminum-in-hornblende geobarometer with application of Long Valley caldera (California) volcanic rocks. Geology, 17:837-841.

King P.L., White A.J.R., Chapell B.W., Allen C.M. (1997). Characterization and origin of aluminous A-type granites from the Lachlan Fold Belt, Southeastern Australia. Journal of Petrology, 38:371-391. 
Lages G.A. (Org.). (2012). Geologia e recursos minerais da Folha Boqueirão SB.24-Z-D-III: Estado da Paraíba. $1^{\text {a }}$ ed. Recife: CPRM, 248p.

Lages G.A. (2013). Geologia e recursos minerais da folha Boqueirão, estado da Paraíba. Recife: CPRM. 248 p.

Lages G.A., Brasilino R G., Miranda A.W.A., Marinho M.S., Medeiros V.C. (2009). Caracterização geoquímica dos ortognaisses do Complexo Cabaceiras (CCB), no Domínio Alto Moxotó, NE do Brasil. In: XII C.B de Geoquímica, Ouro Preto.

Lages G.A., Dantas E.L., Rodrigues J.B., Santos L.M.L. (2013). O magmatismo estateriano/caliminiano e os ortognaisses Coloete: indício geoquímico de granito orogênico no leste da Província Borborema. In: XXV Simpósio de Geologia do Nordeste, Gravatá, p. 509-510.

Lages G.A., Marinho M.S. (2010). Programa Geologia do Brasil. Carta Geológica Escala 1:100 000: Folha SB.24-Z-D-III, Boqueirão. CPRM Serviço Geológico do Brasil. Disponível em <http://geobank. sa.cprm.gov.br/pls/publico/geobank.documents.open_zipfile?id_ sessao $=20150827181910 \&$ file $=$ boqueirao.zip $>$. Acesso em 01 de jan. de 2015

Lages G.A., Marinho M.S., Brasilino R.G. (2011). Pluton Bravo: Granito trans-alcalino pós-colisional, sin a tardi-transcorrência, Província Borborema. In: XIII Congresso Brasileiro de Geoquímica, Gramado, p. 130.

Lages G.A., Marinho M.S., Nascimento M.A.L., Medeiros V.C., Dantas E.L., Fialho D. (2014). Mar de Bolas do Lajedo do Pai Mateus, Cabaceiras, PB: Campo de matacões graníticos gigantes e registros rupestres de civilização pré-colombiana. In: Winge M., Schobbenhaus C., Souza C.R.G., Fernandes A.C.S., Berbert-Born M., Sallun Filho W., Queiroz E.T. (Org.). Sítios Geológicos e Paleontológicos do Brasil. $1^{\mathrm{a}}$ ed. Brasília: CPRM, v. 3, p. 99-112.

Lages G.A., Marinho M.S., Rodrigues J.B., Medeiros V.C., Rodrigues S.W. de O., Viery J.F. (2010). Sm-Nd isotopic patterns and new paleoproterozoic nuclei basement on boundary between Alto Pajeú and Alto Moxotó domains, Borborema Province, NE-Brazil. In: VII SSAGI - South American Symposium on Isotope Geology, Brasília: Unb, 2010. v. 1. p. 20-23.

Leake B.E., Woolley A.R., Arps C.E.S., Gilbert M.C., Grice J.D., Hawthorne F.C., Kisch H.J., Krivovichev V.G., Canada J.A.M., Maresch W.V, Schumacher J.C., France D.C.S., Stephenson N.C.N., Whittaker E.J.W. (1997). Nomenclature of amphiboles. Canadian Mineralogist, 35:219-246.

Liegeois J.P. (1998). Preface: Some words on post-collisional magmatism. Lithos, 45:15-17.

Loiselle N.C., Wones D.R. (1979). Characteristics and origin of anorogenic granites. Geological Society of America - Search Meetings (2) Abstracts, 11:468.

Maniar P.D., Piccoli P.M. (1989). Tectonic discrimination of granitoids. Geological Society of America Bulletin, 101(5):635-643.

Mariano G., Neves S.P., Silva Filho A.F. da., Guimarães I.P. (2001). Diorites of the high-K calc-alkalic Association: Geochemistry and Sm-Nd Data and Implications for the evolution of the Borborema Province, Northeast Brazil. International Geology Review, 10(10):921-929.

Marinho M.S., Lages G.A., Cruz R.F., Medeiros V.M. (2008). Aspectos de campo e petrográficos de diopsídio-mármores da região de Cabaceiras-Boqueirão (PB). In: XLIV Congresso Brasileiro de Geologia. Curitiba: SBG, p. 1035.

Mateinni M., Junges S.L., Dantas E.L., Pimentel M.M., Buhn B.M. (2009). In situ zircon U-Pb and Lu-Hf isotope systematic on magmatic rocks: Insights on the crustal evolution of the Neoproterozoic Goiás Magmatic Arc, Brasília belt, Central Brazil. Gondwana Research, 16:200-212
Middlemost E.A.K. (1997). Magmas, rocks and planetary development. Harlow: Longman.

Nardi L.V.S., Bitencourt M.F. (2009) A-type granitic rocks in postcollisional settings in southernmost Brazil: their classification and relationship with tectonics and magmatic series. Canadian Mineralogist, 47(6):1493-1503.

Neves S.P. (2003). Proterozoic history of the Borborema province (NE Brazil): Correlations with neighboring cratons and Pan-African belts and implications for the evolution of western Gondwana. Tectonics, 22(4):1031-1045.

Neves S.P, Bruguier O., Vauchez A., Bosch D., Silva J.M.R., Mariano G. (2006). Timing of crust formation, deposition of supracrustal sequences, and Transamazonian and Brasiliano metamorphism in the East Pernambuco belt (Borborema Province, NE Brazil): Implications for western Gondwana assembly. Precambrian Research, 149:197-216.

Neves S.P., Lages G.A., Brasilino R.G., Miranda A.W.A. (2015). Paleoproterozoic accretionary and collisional processes and the build-up of the Borborema Province (NE Brazil): Geochronological and geochemical evidence from the Central Domain. Journal of South American Earth Sciences, 58:165-187. doi:10.1016/j. jsames.2014.06.009

Neves S.P., Mariano G. (1997). High-K calc-alkalic plutons in Northeast Brazil: origin of the biotite diorite/quartz monzonite to granite association and implications for the evolution of the Borborema Province. International Geology Review, 39:621-638.

Neves S.P., Mariano G. (2001). Província Borborema: orógeno acrescionário ou intracontinental? Estudos Geológicos, 11:26-36.

Neves S.P., Mariano G., Silva J.M.R. (2010). Programa Geologia do Brasil. Carta Geológica Escala 1:100.000: Folha SB.25-Y-C-IV, Surubim. CPRM - UFPE. Disponível em: <http://geobank.cprm.gov.br/ pls/publico/geobank.download.downloadlayouts?p_webmap=N\&p_ usuario=1>. Acesso em 08 de fev. de 2016 .

Patiño Dolce A.E. (1997). Generation of metaluminous A-type granites by low-pressure melting of calc-alkaline granitoids. Geology, 25(8):743-746.

Pearce J.A. (1996). Sources and settings of granitic rocks. Episodes, 19(4):120-125.

Rodrigues S.W.O., Brito Neves B.B. (2008). Padrões isotópicos Sm-Nd no limite entre os terrenos Alto Pajeú e Alto Moxotó (PB). Revista Brasileira de Geociências, 38(1):209-225.

Santos E.J. (1996). Ensaio preliminar sobre terrenos e tectônica acrescionária na Província Borborema. In: XXXIX Congresso Brasileiro de Geologia, Salvador: SBG, 7v., il., v.6, p .47-50.

Santos E.J. (2000). Contexto Tectônico Regional. In: Medeiros, V. C. (Ed.) Programa de Levantamentos Geológicos Básicos do Brasil: Aracaju NE, Folha SC.24-X. Escala 1:500.000. Brasília: CPRM. CD-ROM.

Santos E.J., Souza Neto J.A., Carmona L.C.M., Armstrong R., Santos L.C.M.L., Mendes L.U.D.S. (2013). The metacarbonate rocks of Itatuba (Paraíba): A record of sedimentary recycling in a Paleoproterozoic collision zone of the Borborema province, NE Brazil. Precambrian Research, 224:454-471. doi:10.1016/j.precamres.2012.09.021

Santos E.J., Van Schmus W.R., Brito Neves B.B., Oliveira R.G., Medeiros V.C. (1999). Terrane and their boundaries in the Proterozoic Borborema Province, Northeast Brazil. In: VII Simpósio Nacional de Estudos Tectônicos (SNET), p. 121-124.

Schmidt M.W. (1992). Amphibole composition in tonalite as a function of pressure: an experimental calibration of the Al-inhornblende-barometer. Contributions to Mineralogy and Petrology, 110:304-310. 
Schumacher J.C. (1997). Appendix 2: the estimate of ferric iron in electron microprobe analysis of amphiboles. Canadian Mineralogist, 35:238-246.

Sial A.N. (1986). Granites types of northeast Brazil: current knowledge. Revista Brasileira de Geociências, 16(1):54-72.

Sial A.N. (1989). Petrologia, geoquímica de elementos maiores, traços, terras raras e isótopos nos Batólitos de Meruoca e Mocambo, Ceará. Recife, Thesis (for Full Professor) - Department of Geology, Federal University of Pernambuco, $284 \mathrm{p}$.

Thompson R.N. (1982). Magmatism of the British Tertiary volcanic Province. Scottish Journal of Geology, 18:50-107.

Väisänen M., Mänttäri I., Kriegsman L.M., Hölttä P. (2000). Tectonic setting of post-collisional magmatism in the Paleoproterozoic Svecofennian Orogen, SW Finland. Lithos, 54:63-81.

Van Schmus W.R., Kozuch M., Brito Neves B.B. (2011). Precambrian history of the Zona Transversal of the Borborema Province, NE Brazil: Insights from Sm-Nd and U-Pb geochronology. Journal of Geotechnical Earthquake Engineering, 31:227-252.
Vauchez A., Neves S., Caby R., Corsini M., Egydio-Silva M., Arthaud M., Amaro V. (1995). The Borborema shear zone system, NE Brazil. Journal of South American Earth Sciences, 8:247-266.

Ventura Santos R., dos Santos E.J., Souza Neto J.A.D., Carmona L.C.M., Sial A.N., Mancini L.H., Santos L.C.M. de L., do Nascimento G.H., Mendes L.U.S., Anastácio E.M.F. (2013). Isotope geochemistry of Paleoproterozoic metacarbonates from Itatuba, Borborema Province, Northeastern Brazil: Evidence of marble melting within a collisional suture. Gondwana Research, 23(1):380-389. doi:10.1016/j. gr.2012.04.010

Watson E.B., Harrison T.M. (1983). Zircon saturation revisited: temperature and composition effects in a variety of crustal magma types. Earth and Planetary Science Letters, 64:295-304.

Whalen, J. B., Currie, K. L., Chappell, B. W. (1987). A-types granites: geochemical characteristics, discrimination and petrogenesis Contributions to Mineralogy and Petrology, 95:407-419.

Arquivo digital disponível on-line no site www.sbgeo.org.br 